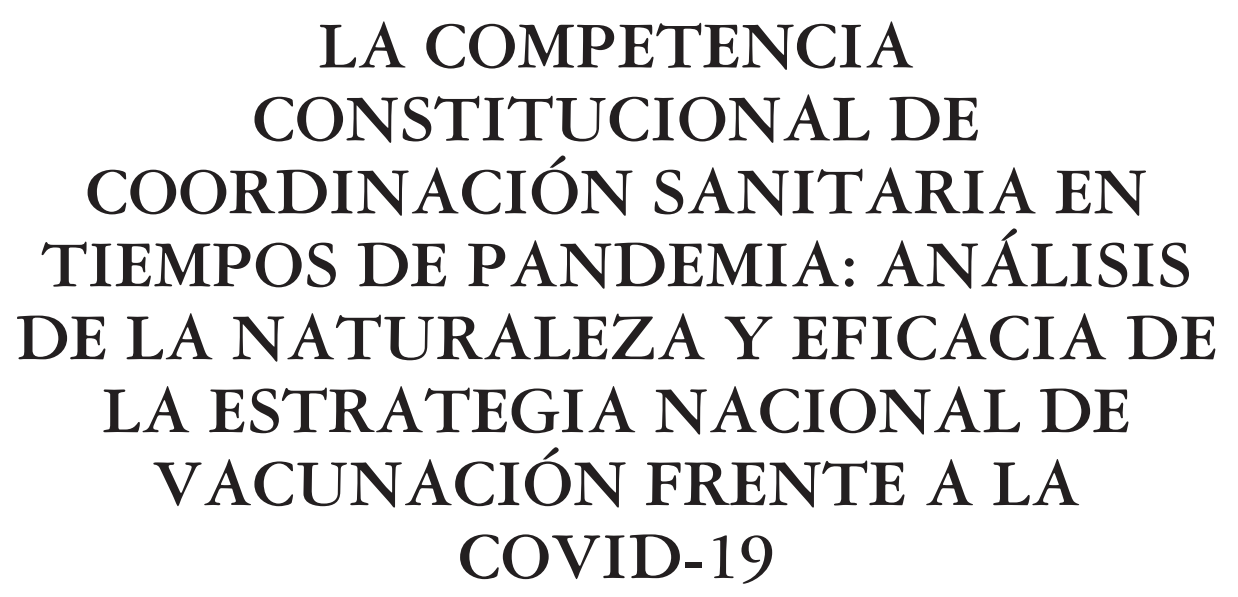

FEDERICO DE MONTALVO JÄÄSKELÄINEN 


\section{SUMARIO:}

\section{INTRODUCCIÓN: DE LA INMUNIDAD POR INFECCIÓN A LA INMUNI- DAD POR VACUNACIÓN; 2. LA ESTRATEGIA COMO INSTRUMENTO DE PRIORIZACIÓN DE UN RECURSO ESCASO. 3. NATURALEZA JURÍDICA DE LA ESTRATEGIA. 3.1. Razones para la determinación de la naturaleza jurídica de la Estrategia: de la imposición de la vacunación a los ciudadanos a la imposición de la Estrategia a las Comunidades Autónomas. 3.2. Naturaleza jurídica del Consejo Interterritorial: ¿Conferencia Sectorial o mero órgano colegiado estatal con represen- tantes autonómicos? 3.2.1. Introducción. 3.2.2. Las competencias de cooperación y coordinación. 3.2.3. El Consejo Interterritorial como expresión institucionalizada del sistema de relaciones interadministrativas. 3.3. La función de actuaciones coordinadas en materia de salud pública.}




\title{
LA COMPETENCIA CONSTITUCIONAL DE COORDINACIÓN SANITARIA EN TIEMPOS DE PANDEMIA: ANÁLISIS DE LA NATURALEZA Y EFICACIA DE LA ESTRATEGIA NACIONAL DE VACUNACIÓN FRENTE A LA COVID-19
}

\author{
FEDERICO DE MONTALVO JÄÄSKELÄINEN* \\ Universidad Pontificia Comillas (ICADE) \\ La coordinación viene a ser asi al modo de \\ extraño personaje del que por todas partes se \\ habla, pero al que por ninguna parte se ve \\ (Luis de la Morena, 1965).
}

\section{INTRODUCCIÓN: DE LA INMUNIDAD POR INFECCIÓN A LA INMUNIDAD POR VACUNACIÓN}

La vacunación frente a la enfermedad de la Covid-19 constituye, en atención a las evidencias científicas actuales, la única alternativa que nos va a permitir superar de manera más o menos definitiva la pandemia y recuperar la normalidad. Y ello, sobre todo, si atendemos a la experiencia de otros países de nuestro entorno que optaron, en los inicios de la pandemia, por otra alternativa como fue la de alcanzar la inmunidad de grupo por contagio, con unos resultados bastante catastróficos ${ }^{1}$.

* Profesor propio agregado, Derecho Constitucional, UPCOmillas (ICADE). Facultad de Derecho. C/ Alberto Aguilera 23 - 28015 Madrid. Email: fmontalvo@icade.comillas.edu ORCID ID: https:// orcid.org/0000-0002-9272-7359

Véase, la Declaración del Comité de Bioética sobre la estrategia de vacunación frente a la covid-19 y, en especial, sobre la priorización de la vacunación de 14 de diciembre de 2020, p. 1. Puede 
La inmunidad de grupo, también denominada inmunidad de rebaño, es definida por la Organización Mundial de la Salud (OMS) como la protección indirecta contra una enfermedad infecciosa que se consigue cuando una población se vuelve inmune, ya sea como resultado de la vacunación o de haber presentado la infección con anterioridad $^{2}$. Se basa, pues, en que, alcanzando la mayor parte de la población la inmunidad frente a una enfermedad infecciosa por haber desarrollado los correspondientes anticuerpos, esto proporciona protección indirecta a quienes no son inmunes. Las personas inmunes actuarían como una especie de cortafuegos impidiendo que el agente alcance a los que no están protegidos. En el caso de SARS-CoV-2 se ha estimado que esta inmunidad de rebaño surge cuando más del $70 \%$ de las personas están protegidas. Uno de los factores que afectan a este valor es el $\mathrm{R}_{0}$ (número reproductivo básico), que estima a cuántas personas puede transmitir un individuo infectado un determinado agente ${ }^{3}$.

Los ejemplos de Suecia, Reino Unido o Estados Unidos de América resultan ciertamente paradigmáticos sobre cuáles son los resultados de tratar alcanzar la inmunidad de grupo por infección. En el caso de Suecia, la opción se basó en criterios científicos que combinaron la protección de los más vulnerables con cierta tolerancia de la propagación del virus entre los que lo eran menos ${ }^{4}$. En el país escandinavo se optó por confiar en un enfoque de cooperación entre la respuesta del Derecho y las correspondientes medidas coercitivas y la responsabilidad individual de las personas para reducir la propagación del virus sobre la base del que ahí denominan, «folkvett», lo que puede traducirse como el sentido común de los suecos como comunidad.

Sin embargo, pronto se comprobó lo desacertado de dicha opción frente a la única otra alternativa en dicho momento, al menos, para mitigar la expansión del virus, el confinamiento y la restricción de la libertad de movimientos de la población. Y aquella medida fue ya errónea desde los primeros días de la crisis de salud pública, no solo por el número de víctimas mortales que suponía (más del $2 \%$ de la población total), sino por el porcentaje de personas que con la infección desarrollarían una enfermedad grave (20\%), lo que provoca, necesariamente, el colapso del sistema sanitario y, por ende, el incremento de la mortalidad por la imposibilidad de atender a los enfermos en situación de compromiso vital. Los ingresos hospitalarios y la mortalidad pronto ofrecieron unos datos mucho peores que los de sus vecinos en los que sí se optó por la

accederse a dicha Declaración a través de la página web del citado Comité, en http://assets.comitedebioetica.es/files/documentacion/Declaracion\%20del\%20CBE\%20-\%20Estrategia\% 20priorizacion\%20 vacunacion\%20frente\%20COVID19.pdf. Último acceso el 1 de mayo de 2021.

2 Vid. https://www.who.int/es/news-room/q-a-detail/herd-immunity-lockdowns-and-covid-19. Último acceso el 1 de mayo de 2021.

3 Vid. https://www.ucm.es/otri/noticias-que-es-la-inmunidad-de-rebano-y-por-que-reino-unidocree-que-puede-funcionar. Último acceso el 1 de mayo de 2021.

4 ORLOWSKI, E.J. y GOLDSMITH, D.J.A., «Four months into the COVID-19 pandemic, Sweden's prized heRD immunity is nowhere in sight», Journal of the Royal Society of Medicine, vol. 11, núm. 8, pp. 292 a 298. 
medida de confinamiento (véase, los casos de Noruega o Finlandia) ${ }^{5}$, y no solo durante los meses inmediatamente posteriores a la declaración de la pandemia por la OMS, sino con una persistencia continuada de una infección y una mortalidad más altas mucho más allá del periodo inicial.

La propia OMS, desde los primeros días de la pandemia, apoyó que la inmunidad colectiva solo podía lograrse a través de la vacunación, no debiéndose permitir que la enfermedad se propagase en un grupo demográfico, ya que ello daría como resultado que se presentaran casos y defunciones innecesarios ${ }^{6}$. También la UNESCO, a través de la «Declaración sobre la Covid-19: consideraciones éticas desde una perspectiva global» (Statement on covid-19: ethical considerations from a global perspective) aprobada el 6 de abril de 2020 por el Comité Internacional de Bioética, IBC, y el Comité de Ética sobre el conocimiento científico y tecnológico, $\mathrm{COMEST}^{7}$, consideró que la alternativa de la inmunidad colectiva exige una revisión ética muy cautelosa, considerando su impacto en el número de casos potencialmente mortales y las posibles condiciones médicamente insostenibles debido a la falta de disponibilidad de instalaciones de cuidados intensivos, incluso en los países desarrollados, lo que podía tener consecuencias negativas para la salud y la seguridad de las personas y la colectividad.

Tampoco ha resultado ser una alternativa plausible para atajar la expansión y las consecuencias de la pandemia, más allá, de momentos puntuales, el sistema de confinamientos y de limitación de derechos y libertades fundamentales, y no solo porque no permitan lograr controlar definitivamente la propagación de la enfermedad y, por tanto, impidan una deseable recuperación económica de la comunidad, sino, además, porque la regla de excepcionalidad constitucional en la que dichas medidas se asientan no puede constituir una regla de normalidad en un Estado de Derecho. Y, además, no debemos olvidar que tanto la inmunidad de grupo por infección como el confinamiento como estrategias frente a la pandemia afectan singularmente a los colectivos de la sociedad más vulnerables.

\section{LA ESTRATEGIA COMO INSTRUMENTO DE PRIORIZACIÓN DE UN RECURSO ESCASO}

El desarrollo y correspondiente autorización de las vacunas frente a la Covid-19 ha superado las expectativas más halagüeñas sobre los plazos en los que tendríamos a

5 HABID, H., «Has Sweden's controversial covid-19 strategy been successful?», BMJ, núm. 369, año 2020

6 Vid. https://www.who.int/es/news-room/q-a-detail/herd-immunity-lockdowns-and-covid-19. Último acceso el 2 de mayo de 2021.

7 Puede accederse a dicha Declaración a través de la web de la UNESCO, en https://en.unesco. org/news/unesco-experts-urge-collective-responsibility-protect-vulnerable-persons-global-battle-against. Último acceso el 5 de mayo de 2021.

(C) UNED. Revista de Derecho Político 
nuestra disposición dicha herramienta esencial para superar esta crisis de salud. La esperanza que ofrecía la llegada temprana de las primeras vacunas, avaladas, además, por unos primeros datos en los ensayos clínicos muy optimistas sobre su inicial seguridad y eficacia, exigía establecer a la mayor brevedad un marco de priorización en el acceso por la población a las vacunas, en la medida que era esperable que el número inicial de dosis solo permitiera inmunizar en las primeras semanas o, incluso, meses, a una parte de la población. El recurso sería inicialmente escaso y, por ello, era importante trabajar en la determinación de unos criterios de priorización.

La propia experiencia con la priorización de los respiradores y demás medidas de soporte vital que tuvo lugar en los primeros días de la pandemia nos había enseñado que la tarea no era sencilla ni que podía hacerse de manera precipitada ${ }^{8}$. A estos efectos, el Comité de Bioética de España en su Informe sobre los aspectos bioéticos de la priorización de recursos sanitarios en el contexto de la crisis del coronavirus, de 25 de marzo de 2020, señalaba que, si bien la priorización de recursos sanitarios es algo inherente a cualquier sistema de salud, ya que el todo, para todos, siempre y ya casi nunca es posible, en el contexto en el que produce esta necesidad de priorizar la hace más trágica por la premura con la que han de adoptarse las decisiones y las consecuencias que entrañan, debiendo dejarse espacios para la deliberación y reflexión y para también atender al principio de igualdad que consagra nuestra Constitución, de manera que habrá que adoptar unos criterios en la asignación de recursos que sean comunes para todos los españoles, de modo que no se produzcan graves inequidades asistenciales ${ }^{9}$.

Y sobre la priorización en el acceso a las vacunas, el mismo Comité de Bioética de España había señalado en su siguiente Informe sobre los requisitos ético-legales en la investigación con datos de salud y muestras biológicas en el marco de la pandemia de covid-19, de 28 de abril de 2020, que en relación con la futura vacuna contra la enfermedad de Covid-19, «es fácil prever que cuando se obtenga una vacuna eficaz para prevenir la infección por virus SARS-CoV-2, será harto difícil poder acceder de manera más o menos inmediata a un número suficiente de dosis para poder facilitársela a toda la población que aún no haya superado la infección y desarrollado la

8 Vid., entre otros, DE MONTALVO JÄÁSKELÄINEN, F. y BELLVER CAPELLA, V., «La Bioética en tiempos del coronavirus: una reflexión acerca de algunos dilemas éticos-legales de la pandemia a partir del Informe del Comité de Bioética de España», en ATIENZA MACÍAS, E. y RODRÍGUEZ AYUSO, J.F. (Dir.), Las respuestas del Derecho a las crisis de salud pública, Dykinson, Madrid, 2020, pp. 243 a 264; DE MONTALVO JÄÁSKELÄINEN, F. y BELLVER CAPELLA, V., «Priorizar sin discriminar: la doctrina del Comité de Bioética de España sobre derechos de las personas con discapacidad en un contexto de pandemia», IgualdadES, 3, pp. 313 a 341; y DE MONTALVO JÄÁSKELÄINEN, F., «Pandemias, política y ciencia: el papel de la ciencia y los científicos en la solución de los conflictos derivados de la pandemia de la covid-19», Cuadernos de Bioética, vol. 31, núm. 102, año 2020, pp. 151 a 165.

9 Puede accederse a dicho Informe a través de la página web del Comité, en http://assets.comitedebioetica.es/files/documentacion/Informe $\% 20$ CBE- $\% 20$ Priorizacion $\% 20 \mathrm{de} \% 20$ recursos $\% 20$ sanitarios-coronavirus\%20CBE.pdf., p. 4 y 6. Último acceso el 1 de mayo de 2021. 
correspondiente inmunidad protectora». $\mathrm{Y}$ «todo ello implicará ineludiblemente la necesidad de establecer una priorización en la aplicación de la vacuna» ${ }^{10}$.

Vista la previsible llegada de las primeras vacunas a principios de 2021, el Consejo Interterritorial del Sistema Nacional de Sanidad, en su reunión plenaria del 9 de septiembre de 2020, al amparo del acuerdo de la Conferencia de Presidentes celebrada el 4 de septiembre anterior, en la que se confirmó la necesidad de seguir avanzando en la estrategia de cogobernanza como la mejor garantía para afrontar de manera conjunta los desafíos que plantea la lucha contra la pandemia provocada por el COVID-19, acordó poner en marcha una estrategia común de vacunación que se elaboraría por un grupo de expertos y se aprobaría en el Pleno del propio Consejo Interterritorial $^{11}$. El denominado Grupo de Trabajo Técnico de Vacunación Covid-19, sería coordinado por el Ministerio de Sanidad a través de la Dirección General de Salud Pública, formando parte del mismo ocho miembros de la Ponencia de Programa y Registro de Vacunaciones del Consejo Interterritorial, especialistas de sociedades científicas, de bioética, sociología, metodología, así como expertos del Instituto de Salud Carlos III, de la Agencia Española de Medicamentos y Productos Sanitarios, del Centro de Coordinación de Alertas y Emergencias Sanitarias y del área de Salud Laboral del Ministerio ${ }^{12}$.

El citado grupo de expertos quedó constituido a finales del mes de septiembre, iniciando sus trabajos de manera inmediata y fruto de ello se publicó el 2 de diciembre de 2020 en la página web del Ministerio de Sanidad la denominada Estrategia de vacunación frente a COVID- 19 en España ${ }^{13}$.

Como se señala al inicio de la Estrategia, conociéndose que la disponibilidad de vacunas será limitada en los primeros meses, «es necesario establecer las líneas fundamentales que deben seguirse, incluyendo la priorización en la vacunación de diferentes grupos de población y de acuerdo con los diferentes fases o periodos en los que se irán recibiendo las correspondientes dosis de la o las vacunas» (página 14).

La Estrategia ha tenido ya seis actualizaciones, la primera de 18 de diciembre de 2020, la segunda de 21 de enero de 2021, la tercera de 9 de febrero de 2021, la cuarta el 26 de febrero de 2021, la quinta el 30 de marzo de 2021 y la última a la fecha de elaboración de este trabajo el 20 de abril de $2021^{14}$. Las actualizaciones

10 Puede accederse a dicho Informe a través de la página web del Comité, en http://assets.comitedebioetica.es/files/documentacion/Informe\%20CBE\%20investigacion\%20COVID-19.pdf, p. 6. Último acceso el 2 de mayo de 2021.

11 https://www.lamoncloa.gob.es/serviciosdeprensa/notasprensa/sanidad14/Paginas/2020/090920-covid-sns.aspx. Último acceso el 2 de mayo de 2021.

12 Vid. Acuerdo del Plenario del Consejo Interterritorial del SNS de 28 de enero de 2021.

13 Puede accederse a la Estrategia a través de la web del Ministerio de Sanidad, en https:/www. mscbs.gob.es/profesionales/saludPublica/prevPromocion/vacunaciones/covid19/docs/COVID-19_EstrategiaVacunacion.pdf. Último acceso el 1 de mayo de 2021.

14 Puede accederse a las actualizaciones a través del siguiente enlace: https://www.mscbs.gob. es/profesionales/saludPublica/ccayes/alertasActual/nCov/vacunaCovid19.htm. Último acceso el 8 de mayo de 2021.

(C) UNED. Revista de Derecho Politico

N. ${ }^{\circ} 112$, septiembre-diciembre 2021, págs. 43-77 
obedecen a que la propia Estrategia en su documento inicial se define como un «documento vivo», que «se irá actualizando a medida que fuera aumentando el conocimiento de las vacunas candidatas y aquellas próximas a su autorización, con los resultados de los ensayos clínicos que se están realizando, las características en cuanto a su logística, almacenamiento y administración, así como detalles sobre la inmunidad generada tras la enfermedad» (página 5). La misma idea se reitera en la segunda, tercera cuarta y quinta actualización. En esta última señala a este respecto, literalmente, que «la Estrategia es un documento vivo y se va modificando a medida que se van recibiendo las vacunas en nuestro país y autorizando diferentes vacunas, se va ampliando el conocimiento y el contexto de la pandemia va cambiando. Por ello, siendo importante establecer una planificación a medio plazo, se realiza sin perjuicio de que habrá que seguir evaluando todos estos elementos» (páginas $4 \mathrm{y}$ 5). También la sexta actualización se refiere a este carácter de documento vivo en prácticamente idénticos términos (página 5).

Pues bien, hecha esta introducción, vamos a analizar, a continuación, una de las principales cuestiones de interés, desde una perspectiva jurídica, sobre la citada Estrategia: cuál es su naturaleza jurídica y, por tanto, eficacia. Ello nos va a permitir, además, hacer una reflexión sobre los instrumentos de coordinación de las políticas sanitarias en tiempos como los presentes, en los que la toma de decisiones conjunta por parte de las diferentes Administraciones Públicas constituye no solo un imperativo desde la perspectiva del principio de igualdad en sede territorial que consagra el art. 149.1.1. ${ }^{a} \mathrm{CE}$, sino también desde las exigencias de protección de la salud que se derivan del art. $43 \mathrm{CE}$, en conexión con el art. 15 CE. Y también, dentro del estudio de la coordinación sanitaria, tendremos la oportunidad de detenernos sobre la controvertida naturaleza de uno de los principales instrumentos institucionalizados para llevar a cabo aquélla, el Consejo Interterritorial del Sistema Nacional de Salud.

\section{NATURALEZA JURÍDICA DE LA ESTRATEGIA}

\subsection{Razones para la determinación de la naturaleza jurídica de la Estrategia: de la imposición de la vacunación a los ciudadanos a la imposición de la Estrategia a las Comunidades Autónomas}

El debate acerca de la naturaleza jurídica de la Estrategia no ha ocupado de manera relevante, por ahora, ni a la doctrina ni a la opinión pública. En el mes de febrero de 2021 algún medio se hacía eco de la falta de naturaleza normativa de la misma, sobre todo, en relación con los presuntos casos de abusos o privilegios en el acceso de las vacunas. Así, se apuntaba que, dado que la Estrategia no tenía carácter normativo alguno y, por ende, coercitivo, su incumplimiento no podía ser susceptible de sanción 
administrativa para aquellos que se habían vacunado, incumpliendo el orden de priorización y prelación establecido en la Estrategia ${ }^{15}$.

Algún jurista llegó a tildar a la Estrategia de seudonorma no exigible, acompañando dichos términos de una denuncia de la degradación en la que se estaba sumiendo nuestro Estado de Derecho, con expresiones tan lapidarias como que «la ingrata realidad es que quienes nos gobiernan han decidido prescindir de normas elementales del Derecho y, en realidad, del propio Derecho; es decir, del Estado de Derecho». Y se concluía que «el plan de vacunación contra el coronavirus se encuentra en un limbo jurídico. Hablamos de actuaciones que pueden afectar al derecho a la vida, a la salud, a la integridad física. Hablamos de un plan que moviliza a todo el sector sanitario y que se presenta como la estrategia básica para terminar con un prolongado estado excepcional de alarma que ha limitado (por no decir, en algunos casos, suspendido) derechos fundamentales. Sin embargo, no es norma jurídica, no está publicado formalmente. No tiene forma (no es una ley, ni un Real Decreto, ni una Orden Ministerial), no tiene rango, no tiene la característica de acto administrativo, no tiene pie de recurso. Sólo se lo puede definir por lo que no es. No existe jurídicamente, pero existe materialmente» ${ }^{16}$.

En términos menos extremos, algún otro jurista sí que consideró que la Estrategia no era vinculante, perteneciendo a la categoría del softlaw (sic!), al emanar directamente del grupo de expertos y no estar publicada oficialmente en el correspondiente Boletín. Sin embargo, sí se apuntaba que ello podría no haber sido así si el Ministerio de Sanidad hubiera tratado de revestir esta Estrategia del carácter de declaración de actuaciones coordinadas, previsto en la Ley de Cohesión y Calidad o bien, en su caso, hubiera promovido los mecanismos para articular esta estrategia como norma básica y, por tanto, de obligado cumplimiento sin perjuicio del posterior desarrollo autonómico, por las comunidades autónomas ${ }^{17}$.

Esta falta de excesiva atención, en concreto, a la valoración jurídica de la Estrategia responde, en cierto modo, a que las reflexiones jurídicas sobre cuestiones de salud pública han sido más bien escasas en nuestra doctrina científica, en comparación con, por ejemplo, los estudios y páginas dedicadas a los problemas legales de la sanidad asistencial (véase, el consentimiento informado o el acceso a la historia clínica). Como recordara hace ya unos años CIERCO SIEIRA, si bien la preocupación del Estado por

15 Véase, la edición on line de El Mundo de 6 de febrero de 2021. Puede accederse a la noticia bajo el título de «El plan de vacunación, en el limbo jurídico» a través del siguiente enlace: https://www. elmundo.es/espana/2021/02/05/601db203fdddffa05e8b4680.html. Último acceso el 3 de mayo de 2021.

16 DEL CARPIO FIESTAS, V., «La estrategia de vacunación del coronavirus: la nada jurídica para luchar contra la pandemia», 23 de enero de 2021. Puede accederse a dicho artículo a través del blog jurídico al que puede accederse a través del siguiente enlace: https://elotroblogdeveronicadelcarpio. com/2021/01/23/estrategia-vacunacion/. Último acceso el 3 de mayo de 2021.

17 Véanse, las declaraciones del profesor Joaquín Cayón a Diario Médico y recogidas en la edición web de dicho medio el 3 de febrero de 2021. Puede accederse a las mismas a través del siguiente enlace: https://www.diariomedico.com/medicina/medicina-preventiva/politica/los-camareros-de-ayuso-pueden-ser-priorizados-en-la-vacunacion.html. Último acceso el 3 de mayo de 2021. 
la protección de la salud de su población surge desde el preciso instante en que se constata la existencia de amenazas sanitarias que el individuo, de manera aislada, con sus propios recursos, es incapaz de afrontar con éxito, siendo la función pública de protección de la salud colectiva el aportar medios colectivos para combatir esas amenazas cuyo paradigma no era otro que el de las mortíferas epidemias, durante la segunda mitad del siglo Xx se experimentó un cierto aletargamiento de la materia, motivado, entre otras causas, por el protagonismo que iba adquiriendo la necesidad de construir un sistema sanitario tendente a ofrecer asistencia médica ${ }^{18}$. La salud individual ha centrado en estas décadas el debate y la salud colectiva ha merecido menor atención no solo de la doctrina científica, sino del propio legislador. La propia aprobación de una Ley como la General de Sanidad que poco se ocupa de la salud pública veinticinco años antes de aprobarse y publicarse la Ley General de Salud Pública es un ejemplo paradigmático de todo ello. Y si bien es cierto que la pandemia ha dotado a la salud pública y a las cuestiones jurídicas relacionadas con la misma de una enorme actualidad, siendo ahora el centro de atención de muchos juristas, las bases dogmáticas para el análisis jurídico de las cuestiones y conflictos que semana a semana van planteándose no son excesivamente sólidas o precisas. El análisis jurídico de los conflictos y problemas concretos, como es el de la naturaleza jurídica de la Estrategia supone, habitualmente, una labor menos compleja cuando las bases jurídicas del sistema de salud pública son mínimamente claras. Sin embargo, cuando hasta cuestiones tales como la propia naturaleza del órgano que se encarga de impulsar y aprobar la Estrategia han venido siendo puestas en duda, la tarea se dificulta.

También ESCRIBANO COLLADO recordaba hace unos años que, no solo el campo de la salud pública en general, sino el propio principio de coordinación en el Sistema Nacional de Salud tampoco ha merecido especial atención ni por la doctrina ni por los propios poderes públicos, habiendo estado el mismo Ministerio de Sanidad más preocupado habitualmente por las labores de gestión que le correspondían a través del Instituto Nacional de Salud, INSALUD, y conforme a lo dispuesto en la Disposición Transitoria Tercera de la Ley General de Sanidad, en un sistema asimétrico como el que existió hasta las últimas transferencias sanitarias de principios de este $\operatorname{siglo}^{19}$. A partir de la culminación de las transferencias en el ámbito de la salud, se produce un necesario e importante cambio de posicionamiento de la Administración Sanitaria del Estado. El papel que ahora le corresponde desempeñar, además de la gestión en el ámbito de la sanidad exterior, se limita prácticamente a impulsar la coordinación y cooperación interautonómica o interterritorial, propiciando el consenso y la participación de las Comunidades Autónomas en una puesta

18 CIERCO SIEIRA, C., «Epidemias y Derecho Administrativo. Las posibles respuestas de la Administración en situaciones de grave riesgo sanitario para la población», Derecho y Salud, vol. 13, núm. 2, julio-diciembre 2005, pág. 211.

19 ESCRIBANO COLLADO, P., «La cohesión del Sistema Nacional de Salud. Las funciones del Consejo Interterritorial», Administración de Andalucía. Revista Andaluza de Administración Pública, núm. 52, año 2003, p. 15. 
en común de políticas sanitarias de las que resulte un sistema sanitario coherente y solidario ${ }^{20}$.

Si acudimos al propio tenor literal del documento que contiene la Estrategia, es verdad que pocos elementos vamos a encontrar que puedan ayudarnos a resolver cuál es su naturaleza jurídica. Poco o prácticamente nada dice sobre ello el documento, limitándose a señalar, en un apartado relativo a la gobernanza, que la «elaboración de la Estrategia de Vacunación COVID-19 en España es un mandato del Pleno del Consejo Interterritorial del Sistema Nacional de Salud (CISNS), órgano colegiado de sanidad en el que participan los consejeros de sanidad de las comunidades y ciudades autónomas y el Ministro de Sanidad» (página 15), en el marco del cual, el pasado 9 de septiembre de 2020, se aprobó una Declaración de Actuaciones Coordinadas en materia de Salud Pública que acordó, entre otras, la puesta en marcha de una estrategia de vacunación común para todos los territorios, elaborada de forma conjunta teniendo en cuenta la opinión de expertos en bioética y de sociedades científicas. Es decir, la Estrategia expone cuál el origen y razones de ser de la misma, pero no cuál es su encaje jurídico-formal, aunque ya la mención a la declaración de actuaciones coordinadas permite entenderla como remisión al art. 65 de la Ley 16/2003, de 28 de mayo, de cohesión y calidad del Sistema Nacional de Salud.

En todo caso, para tratar de introducir cierta claridad en el debate, es importante partir de una diferencia relevante y esta es la de determinar qué se pretende con la Estrategia y, sobre todo, para quién deber ser obligatoria y vinculante la misma, si para los ciudadanos o para las Comunidades Autónomas que participan tanto en el Consejo Interterritorial como en el propio grupo de expertos que está elaborando la misma ${ }^{21}$.

Sostener que la Estrategia adolece de unas graves deficiencias legales que ponen en duda su propia virtualidad jurídica y, por ende, la posibilidad de exigir su cumplimiento a los ciudadanos creemos que supone un grave error de interpretación de los fines de la Estrategia. Y ello, porque la Estrategia ni incide ni pretende incidir sobre ninguno de los derechos y libertades de los ciudadanos o, al menos, en lo que se refiere a los derechos sujetos a reserva de Ley y de jurisdicción en los términos que se expresa el art. 53 de la Constitución en sus apartados 1 y 2. Y del tenor de la Estrategia puede perfectamente sostenerse que la misma no afecta ni limita derecho alguno de los consagrados en el Capítulo II del Título I de la Constitución, es decir, los

20 BELTRÁN AGUIRRE, J. L., «La igualdad básica, la coordinación y la cooperación interterritorial: fundamentos del Sistema Nacional de Salud», Derecho y Salud, vol. 10, núm. 2, julio-diciembre 2002, p. 134.

21 En la propia Estrategia y en sus cinco actualizaciones se describen quiénes son los expertos que están asesorando en la elaboración de la misma y, así, desde la perspectiva de las Administraciones Autonómicas Sanitarias, se señala que participan los miembros de la Ponencia del Programa y Registro de Vacunaciones de Andalucía, Canarias, Cataluña, Comunidad Valenciana, Galicia, Madrid, Murcia y País Vasco.

(C) UNED. Revista de Derecho Politico

N.o 112 , septiembre-diciembre 2021, págs. 43-77 
proclamados en los arts. 14 a 38, y más aún, cuando la propia Estrategia afirma que la vacunación no es obligatoria.

Al no incorporar la Estrategia, por tanto, medida ablatoria alguna de los derechos y libertades, entendemos que no tiene prácticamente virtualidad discutir acerca de su vinculación o no para los ciudadanos. Si la Estrategia incorporara entre sus previsiones la vacunación obligatoria, estaríamos hablando de un documento que habría de enmarcarse en las previsiones de la Ley Orgánica 3/1986, y que como tal medida que afecta directamente a derechos como la integridad física o la intimidad, habría de quedar sujeta a un especial escrutinio, no ya de mera legalidad, sino, más allá, de constitucionalidad, tanto desde una perspectiva formal como material. Sin embargo, nada de ello dispone la Estrategia. Si la vacunación fuera obligatoria sí podría afirmarse que ello supone una medida que incide sobre la integridad y la intimidad consagradas en los arts. 15 y 18 de la Constitución y, por ello, debiera quedar sujeta a los requisitos de reserva de ley, reserva de jurisdicción y principio de proporcionalidad.

Sobre la imposición de la vacunación, la estrategia se limita a señalar en su tercera actualización que la vacunación no es obligatoria, idea que reitera en la cuarta y quinta actualizaciones ${ }^{22}$.

Cierto es que ello no impide afirmar que estrategia sea inocua en cuanto a su posible incidencia en materia de derechos, en la medida que a través de las decisiones que aparecen incorporadas a la misma se distribuye un recurso escaso. Ello, en todo caso, afecta, no a un derecho fundamental, ni siquiera a uno de los derechos denominados ordinarios y consagrados en los arts. 30 a 38, sino, llana y simplemente, al derecho a la protección de salud que constituye prima facie un mero principio rector o, en su caso, algo más que un principio, un verdadero derecho con un contenido determinable ${ }^{23}$, pero configurable por los poderes públicos.

En la Sentencia 139/2016, el Tribunal Constitucional nos recuerda que, atendiendo a su ubicación sistemática, el art. 43 CE se configura como un principio rector, razón por la que carece de contenido constitucionalmente esencial que pueda ser afectado por la legislación de urgencia. Debe partirse, en consecuencia, de que el art. 43 CE no ostenta las características de derecho.

Y si bien el art. 43 en su apartado 2 de la Constitución dispone que «compete a los poderes públicos organizar y tutelar la salud pública a través de medidas preventivas y de las prestaciones y servicios necesarios, estableciéndose por Ley los derechos

22 Puede afirmarse que, aún siendo posible la vacunación forzosa en un contexto de grave riesgo para la salud pública como el actual, conforme se deduce de la Ley Orgánica 3/1986, la no necesidad de adoptar tal medida, atendido el porcentaje actual de rechazos a la vacuna frente a la Covid-19, permite presumir que puede alcanzarse el objetivo del $70 \%$ de población vacunada o inmune sin recurrir a una solución ablatoria.

23 SOLOZÁBAL ECHAVARRÍA, J. J., «El derecho constitucional a la salud en el Estado autonómico», en GASCÓN ABELLÁN, M., GONZÁLEZ CARRASCO, M. C. y CANTERO MARTÍNEZ, J., Derecho sanitario y Bioética. Cuestiones actuales, Tirant lo Blanch, Valencia, 2011, p. 66. 
y deberes de todos al respecto», la Ley 14/1986, de 25 de abril, General de Sanidad, señala, en su artículo 3.2, que «el acceso y las prestaciones sanitarias se realizarán en condiciones de igualdad efectiva» y en el artículo 18 recoge las diferentes actuaciones sanitarias que desarrollarán las Administraciones Públicas, a través de sus servicios de salud y de los órganos competentes en cada caso. Asimismo, en el artículo 45 indica que «el Sistema Nacional de Salud integra todas las funciones y prestaciones sanitarias que son responsabilidad de los poderes públicos para el debido cumplimiento del derecho a la protección de la salud». Y por su parte, la Ley 16/2003, de 28 de mayo, de cohesión y calidad del Sistema Nacional de Salud, en su artículo 7.1 establece que «el catálogo de prestaciones del Sistema Nacional de Salud tiene por objeto garantizar las condiciones básicas y comunes para una atención integral, continuada y en el nivel adecuado de atención»; que «se consideran prestaciones de atención sanitaria del Sistema Nacional de Salud los servicios o conjunto de servicios preventivos, diagnósticos, terapéuticos, de rehabilitación y de promoción y mantenimiento de la salud dirigidos a los ciudadanos»; y señala, por último, las prestaciones que comprenderá el catálogo.

El artículo 8 de la citada Ley contempla que las prestaciones sanitarias del catálogo se harán efectivas mediante la cartera de servicios comunes que, según prevé el artículo 20, se acordará en el seno del Consejo Interterritorial del Sistema Nacional de Salud y se aprobará mediante real decreto, teniendo en cuenta en su elaboración la «eficacia, eficiencia, efectividad, seguridad y utilidad terapéuticas, así como las ventajas y alternativas asistenciales, el cuidado de grupos menos protegidos o de riesgo, las necesidades sociales, y su impacto económico y organizativo».

En el caso concreto que nos ocupa, la vacuna constituye una prestación que aparece en la norma que regula el precitado catálogo, el Real Decreto 1030/2006, de 15 de septiembre, por el que se establece la cartera de servicios comunes del Sistema Nacional de Salud y el procedimiento para su actualización, en el apartado 3.1.2 de actividades preventivas: «a) Vacunaciones en todos los grupos de edad y, en su caso, grupos de riesgo, según el calendario de vacunación vigente aprobado por el Consejo Interterritorial del Sistema Nacional de Salud y las administraciones sanitarias competentes, así como aquellas que puedan indicarse, en población general o en grupos de riesgo, por situaciones que epidemiológicamente lo aconsejen».

La Estrategia sería, pues, una decisión pública de ordenación de una prestación reconocida en la correspondiente norma reglamentaria de desarrollo de la Ley 14/1986 y Ley 16/2003, y ello de acuerdo con las condiciones de urgencia del contexto y escasez de las correspondientes dosis o unidades.

En definitiva, la importancia de determinar cuál es la naturaleza jurídica de la Estrategia no deriva de su capacidad de imponerse sobre la voluntad de los ciudadanos, en cuanto limitadora de algún derecho fundamental, lo que ya hemos visto que no hace, sino de la de poder exigirse a las Comunidades Autónomas que intervienen en la misma a través de su presencia en el Consejo Interterritorial. La pregunta no es si la Estrategia puede imponerse a un ciudadano, sino, si puede imponerse a una 
Administración Pública encargada de la vacunación de sus ciudadanos ¿Puede una Comunidad Autónoma alterar el orden de priorización acordado en la Estrategia o, incluso, más aún, no seguir de manera unilateralmente dicho orden y establecer su propia estrategia de vacunación para sus ciudadanos?

\subsection{Naturaleza jurídica del Consejo Interterritorial: ¿Conferencia Sectorial o mero órgano colegiado estatal con representantes autonómicos?}

\subsubsection{Introducción}

La determinación de la naturaleza jurídica de la Estrategia puede establecerse a partir de un criterio objetivo que atienda a las características y ámbito en el que se enmarca la decisión que se contiene en la misma, o subjetivo, a través de la propia naturaleza del órgano que ha aprobado la misma y, a partir de ahí, comprobar si la Estrategia encaja en alguna de las modalidades de decisiones que, ope legis, tiene atribuido dicho órgano.

El órgano que ha aprobado la Estrategia, más allá del grupo de expertos que hace sus recomendaciones y de la Comisión de Salud Pública que hace suyas dichas recomendaciones ${ }^{24}$, es, como ya hemos señalado antes, el Consejo Interterritorial del Sistema Nacional de Salud.

El Consejo Interterritorial del Sistema Nacional de Salud aparece regulado por primera vez en el art. 47.1 de la Ley 14/1986, de 25 de abril, General de Sanidad. Dicha regulación fue derogada tras la aprobación de la Ley 16/2003, de 28 de mayo, de Cohesión y Calidad del Sistema Nacional de Saludd ${ }^{25}$. En la Exposición de Motivos de esta última se dispone, literalmente, que el «órgano básico de cohesión es el Consejo Interterritorial del Sistema Nacional de Salud, al que se dota de mayor agilidad en la toma de decisiones y de mecanismos para la búsqueda de consensos, así como para la vinculación entre las partes en la asunción de estas decisiones». Y añade, a continuación, en la misma Exposición que en «El capítulo VIII aborda las actuaciones coordinadas del Estado y de las comunidades autónomas en materia de

24 Recuérdese que el art. 74 de la Ley 16/2003 prevé que el Consejo Interterritorial pueda crear cuantas comisiones y grupos de trabajo considere necesarios para la preparación, el estudio y desarrollo de las cuestiones sometidas a su conocimiento, siendo, según dispone el art. 71, la salud pública una de sus funciones, tanto en lo que se refiere a la declaración de la necesidad de realizar las actuaciones coordinadas (ap. 1.1), como a los planes y programas sanitarios, especialmente los que se refieren a la promoción de la salud y la prevención de la enfermedad, que impliquen a todas o a una parte de las comunidades autónomas (ap. 2.c).

25 Tal reforma trajo causa de las recomendaciones de la Subcomisión del Congreso de los Diputados para la Consolidación y Modernización del Sistema Nacional de Salud que manifestó la necesidad de fortalecer el papel del Consejo, definiéndolo como el instrumento esencial de vertebración del sistema sanitario. A estos efectos, recomendó otorgarle mayores facultades de decisión. Vid. BELTRÁN AGUIRRE, J. L., «La igualdad básica, la coordinación y la cooperación interterritorial: fundamentos del Sistema Nacional de Salud», Derecho y Salud, vol. 10, núm. 2, julio-diciembre 2002, p. 137. 
salud pública..., cuya declaración corresponderá, respectivamente, al Ministerio de Sanidad y Consumo, previo informe del Consejo Interterritorial del Sistema Nacional de Salud, ..., salvo en casos de urgente necesidad. Estas actuaciones se encuadrarán necesariamente en alguno de los supuestos que se prevén, entre ellos, la necesidad de dar respuesta a situaciones de especial riesgo o alarma para la salud pública». Y «También se contempla la elaboración, por parte del Estado y de las comunidades autónomas, a través del Consejo Interterritorial del Sistema Nacional de Salud, de un plan de cooperación y armonización de actuaciones en el ámbito de la salud pública, dirigido a promover actividades que complementen las realizadas por las distintas Administraciones públicas».

El art. 69 establece que el Consejo es «el órgano permanente de coordinación, cooperación, comunicación e información de los servicios de salud entre ellos y con la Administración del Estado, que tiene como finalidad promover la cohesión del Sistema Nacional de Salud a través de la garantía efectiva y equitativa de los derechos de los ciudadanos en todo el territorio del Estado».

El art. 71 dispone que el Consejo Interterritorial es «el principal instrumento de configuración del Sistema Nacional de Salud y que conocerá, debatirá y, en su caso, emitirá recomendaciones», entre otras, sobre «la declaración de la necesidad de realizar las actuaciones coordinadas en materia de salud pública a las que se refiere esta ley» (art. 71.1 1). Y concluye el citado precepto distinguiendo entre funciones de coordinación del Sistema Nacional de Salud y de cooperación entre el Estado y las comunidades autónomas.

\subsubsection{Las competencias de cooperación y coordinación}

El Consejo Interterritorial encajaría pues dentro de las fórmulas de cooperación y coordinación que resultan indispensables en un Estado descentralizado, habiendo cobrado especial relevancia la segunda, la función de coordinación, tras la reforma del Consejo operada por la ya citada Ley 16/2003, frente al texto original de 1986. El protagonismo en el ejercicio de la función coordinadora recae en el Consejo Interterritorial, y justamente una de las aportaciones más relevantes de la Ley 16/2003 es la reforma y potenciación de dicho órgano, hasta el punto de que el mismo responde ahora a una concepción diferente de la que tuvo inicialmente en la Ley General de Sanidad $^{26}$.

Las citadas dos funciones de cooperación y coordinación responden, como recordara PAREJO ALFONSO, a su consideración común de funciones correctoras de la distribución en una pluralidad de instancias diferenciadas o separadas en paralelo y sus respectivos ámbitos de responsabilidad en la gestión de los asuntos públicos. En el campo que implique la acción de dos o más de las piezas del poder administrativo,

26 PEMÁN GAVÍN, J. M., «La nueva configuración del Sistema Nacional de Salud tras la Ley de cohesión y calidad», Revista Vasca de Administración Pública, núm. 71, año 2005, p. 187. 
exige la superación de la pluralidad, sin anularla, en el resultado, en la realización del interés general objetivo conforme al orden constitucional y, por tanto, la unidad que éste representa ${ }^{27}$. La coordinación es, en general, la ordenada disposición del esfuerzo del grupo a fin de conseguir la unidad de acción en la persecución de un propósito común $^{28}$. Y ello cobra especial relevancia en el ámbito del derecho a la protección de la salud en la que medida que el Estado no solo es autonómico, sino también social de Derecho. El Gobierno central y los autonómicos deben ser vistos, no como competidores por el poder, sino como dos niveles de gobierno que, cooperando entre sí o complementándose, pueden satisfacer las constantes demandas de la sociedad ${ }^{29}$. Porque el principio de coordinación representa el alma misma de la estructura compuesta de poder, como la sustancia que permite la adecuada combinación y síntesis de los dos elementos que entran en reacción en el sistema autonómico: la unidad del conjunto y la autonomía de las partes ${ }^{30}$.

El elemento que caracteriza, fundamentalmente, a la concepción cooperativa en sentido lato o colaborativa (el profesor Parejo incluye tanto la cooperación como la coordinación dentro del concepto en sentido lato, como también hace Eliseo Aja ${ }^{31}$ ) es la forma de ejercicio de las competencias, en el sentido de que tanto el poder central como los poderes autonómicos han de ejercer sus atribuciones no como sujetos aislados sino como partes integrantes de una única estructura de gobierno, que actúa, en definitiva, sobre los mismos ciudadanos, de forma que el Gobierno central y los autonómicos deben ser vistos no como competidores por el poder, sino como dos niveles de gobierno que, cooperando entre sí o complementándose, pueden satisfacer las constantes demandas de la sociedad ${ }^{32}$.

La competencia de coordinación no puede entenderse que atribuya a su titular, el Estado central, potestades para condicionar el ejercicio de las competencias autonómicas ni tampoco, a la inversa, que puede condicionarse al Estado en la elección de las opciones que son de su responsabilidad. La competencia de coordinación alude a que las competencias se desenvuelvan de una manera determinada, con un conocimiento previo de las necesidades, ajustando el ejercicio de las competencias por quien sea su titular hacia objetivos predeterminados elegidos después de contrastar los criterios de todos los entes responsables. Se trataría no tanto de un poder de dirección

27 PAREJO ALFONSO, L., «Notas para una construcción dogmática de las relaciones interadministrativas», RAP, núm. 174, septiembre-diciembre 2007, p. 166.

28 DE LA MORENA Y DE LA MORENA, L., «La coordinación como función: su concepto y problemática», Documentación Administrativa, núm. 94, año 1965, p. 25.

29 TAJADURA TEJADA, J., El principio de cooperación en el Estado Autonómico, 3. a ed., Comares, Granada, 2010, p. 48.

30 ALBERTÍ ROVIRA, E., «La coordinación entre el Estado y las Comunidades Autónomas», Documentación Administrativa, núm. 230-231, año 1992, p. 49. Vid., también, LEÓN ALONSO, M., La protección constitucional de la salud, La Ley, Madrid, 2010.

31 AJA, E., TORNOS, J., FONT, T., PERULLES, J.M. y ALBERTí, E., El sistema jurídico de las Comunidades Autónomas, Tecnos, Madrid, 1985, p. 398.

32 TAJADURA TEJADA, J., El principio de cooperación ..., op. cit., p. 48. 
por el Gobierno central, sino de una conjunción en la formulación de objetivos que las diferentes partes que integran un sistema sanitario deben alcanzar. Y el titular de la competencia, el Estado, debe emplearla para hacer partícipes a las Comunidades Autónomas de sus proyectos y objetivos y para recabar de las mismas información a efectos de formar sus decisiones. Así pues, la coordinación es una directiva que afecta al ejercicio de la competencia, pero no expansiona la competencia estatal ni un ápice más de lo que corresponde a la formulación de las bases, que es, en verdad, el título competencial sustantivo ${ }^{33}$.

La coordinación no sería tanto unidad de acción, sino unidad de resultados, por lo que no siempre ni necesariamente se busca que tales acciones discurran por una misma vía, sino que cualesquiera que sean sus direcciones o trayectorias, autónomamente consideradas, vengan al fin a converger todas ellas en un punto común ${ }^{34}$. La coordinación va, en todo caso, más allá de la mera lealtad federal y supone una idea fuerte de colaboración, una expresión de verdadera dirección ${ }^{35}$.

La función de coordinación resulta claro que no constituye una norma competencial que permita una redistribución de los poderes sustantivos de las partes, una norma que habilite ordinariamente la expansión de la competencia material del Estado, invadiendo sin límite el ámbito de los poderes atribuidos a las Comunidades Autónomas. La coordinación podrá tener como objeto el establecimiento de una homogeneidad técnica y la obligación de una acción conjunta, y sólo podrá producirse en el supuesto de que tales objetivos no se consigan a través del acuerdo voluntario de las partes, acuerdo voluntario que se presenta como el resultado normal y ordinario del procedimiento de coordinación ${ }^{36}$.

La coordinación puede diferenciarse del deber general de colaboración, tanto en su dimensión negativa (como límite que oponen los intereses del conjunto y de las demás instancias) como positiva (auxilio recíproco), pues ni se construye como deber jurídico ni coincide con aquél en su finalidad y contenido específicos ${ }^{37}$.

La competencia estatal en materia de coordinación es, en palabras del Tribunal Constitucional, un título que puede dar origen a actuaciones de tipo normativo y de tipo ejecutivo, incluyendo también facultades para la organización de los entes que las desarrollen. La coordinación es una variedad de la colaboración que conlleva un cierto poder de dirección, consecuencia de la posición de superioridad en que se

33 MUÑOZ MACHADO, S., Derecho Público de las Comunidades Autónomas, Civitas, Madrid, 1982, pp. 573 a 574 . Vid., también, COBREROS MENDAZONA, E., «La coordinación sanitaria estatal y las Comunidades Autónomas», Documentación Administrativa, núm. 230-231, abril-septiembre 1992, pp. 308 a 310 .

34 DE LA MORENA Y DE LA MORENA, L., «La coordinación como función: ...», cit., p. 26.

35 SOLOZÁBAL ECHAVARRÍA, J. J., «El derecho constitucional a la salud en el Estado autonómico», en GASCÓN ABELLÁN, M., GONZÁLEZ CARRASCO, M. C. y CANTERO MARTÍNEZ, J., cit., pp. 75 y 76.

36 COBREROS MENDAZONA, E., «La coordinación sanitaria estatal y las Comunidades Autónomas», Documentación Administrativa, núm. 230-231, abril-septiembre 1992, p. 311.

37 ALBERTÍ ROVIRA, E., «La coordinación entre el Estado ...», cit., pp. 51 y 52.

(C) UNED. Revista de Derecho Politico

N. ${ }^{\circ} 112$, septiembre-diciembre 2021, págs. 43-77 
encuentra el que coordina respecto al coordinado (SSTC 214/1989, FJ 20, f); 109/1998, FJ 13; 194/2004, FJ 8; y 86/2014, FJ 5).

Constituye, por tanto, una competencia estatal que implica la existencia previa de competencias autonómicas que el Estado va a coordinar respetando, en todo caso, su contenido y que se configura como un factor clave en el Estado descentralizado ${ }^{38}$. Incluso, constituye el momento organizativo esencial de todo Estado que, sin constituir una técnica de limitación de la autonomía, permite verificar la regularidad de la actividad de las Comunidades Autónomas ${ }^{39}$, y, añadimos, nosotros, atender al interés general y al principio de igualdad en contextos en los que no basta con una acción fragmentada en la defensa y protección de la salud de los ciudadanos. La exigencia de la cohesión busca el que se de una integración de los entes administrativos que conforman el servicio de salud y un mismo nivel de las prestaciones para todos los ciudadanos, con independencia del territorio autonómico en el que viven o, más precisamente, en el que reciban la asistencia ${ }^{40}$. La competencia estatal de control no será, pues, una competencia como las demás, sino su suplemento esencial, sin que pueda afirmarse de manera correcta que los conceptos de autonomía y de competencia estatal de control se hallen en una relación de dialéctica oposición ${ }^{41}$.

Un sistema de organización territorial que, como el nuestro, lleva a cabo una distribución del poder político entre entes dotados de potestad legislativa propia, implica necesariamente un ordenamiento jurídico complejo. Junto a normas vigentes para toda España, hay otras cuya vigencia está limitada al territorio de la correspondiente Comunidad Autónoma. En relación a la igualdad de derechos de las Comunidades Autónomas se ha manifestado el Tribunal Constitucional señalando que el régimen autonómico se caracteriza por un equilibrio entre la homogeneidad y diversidad del status jurídico público de las Entidades territoriales que lo integran, añadiendo que sin la primera, no habría unidad ni integración en el conjunto estatal; sin la segunda, no existiría verdadera pluralidad ni capacidad de autogobierno, notas que caracterizan al Estado de las Autonomías (STC 76/1983, de 5 de agosto, FJ 2).

En todo caso, cooperación y coordinación son funciones distintas y su diferencia radica en que mientras la primera se ofrece articulada por las notas de voluntariedad, igualdad posicional e imposibilidad de imposición unilateral de cualquier decisión, la coordinación sí que supone, por el contrario, un límite a las competencias, y si bien no comporta sustracción o menoscabo de éstas, sí implica la facultad de decidir, que

38 LEÓN ALONSO, M., La protección constitucional de la salud, La Ley, Madrid, 2010, p. 399.

39 CASCAJO CASTRO, J. L., «Control del Estado sobre las Comunidades Autonómas», en GONZÁLEZ ENCINAR, J. J. (Dir.), Diccionario del Sistema Político Español, Akal, Madrid, 1984, p. 142.

40 SOLOZÁBAL ECHAVARRÍA, J. J., «Bases constitucionales de una posible política sanitaria en el Estado autonómico», Fundación Alternativas, Documento de trabajo 89/2006, disponible en http://www.fundacionalternativas.org/public/storage/laboratorio_documentos_archivos/xmlimport-x7vLy7.pdf, Madrid, 2006, p. 8. Último acceso el 5 de mayo de 2021.

41 CASCAJO CASTRO, J. L., «Control del Estado sobre las Comunidades Autonómas», en GONZÁLEZ ENCINAR, J. J. (Dir.), cit., p. 142. 
hace imposible el respeto total de las competencias implicadas ${ }^{42}$. El juego legítimo de la coordinación quedará restringida a los casos tasados expresamente previstos en la Ley ${ }^{43}$. La coordinación supone, pues, mecanismo más intenso de ajuste, para supuestos determinados, del ejercicio de competencias diversas, incluso, del sistema mismo de reparto de competencias. La coordinación, como ordenada disposición del esfuerzo del grupo a fin de conseguir la unidad de acción en la persecución de un propósito común, no es incompatible con la autonomía, sino un límite al ejercicio de ésta ${ }^{44}$. Se trataría, pues, de un concepto más formal que sustantivo ${ }^{45}$.

La figura del Consejo Interterritorial es, en definitiva, una expresión institucionalizada del sistema de relaciones interadministrativas y que, por tanto, reposa por completo en las dos correspondientes técnicas de dicha interrelación o colaboración indispensable, la cooperación y la coordinación. Es un órgano colegiado de coordinación organizativa que se complementa con la segunda técnica de coordinación contemplada en el ordenamiento sanitario, la planificación (art. 70 de la Ley General de Sanidad $)^{46}$.

La Sentencia del Tribunal Constitucional 32/1983 señala, precisamente en el ámbito de la salud, que la coordinación persigue la integración de la diversidad de las partes o subsistemas en el conjunto o sistema, evitando contradicciones y reduciendo disfunciones que, de subsistir, impedirían o dificultarían respectivamente la realidad misma del sistema. En este sentido hay que entender la competencia estatal de coordinación general, a propósito de la cual conviene señalar las siguientes precisiones: a) aunque constituye un reforzamiento o complemento de la noción de bases, es una competencia distinta a la de fijación de las bases, como se desprende del hecho de que en el art. 149.1 no siempre que se habla de bases se habla también de coordinación general, si bien ésta, cuando se incluye, aparece salvo en una ocasión (149.1.15) unida a la competencia sobre las bases (art. 149.1.13 y 149.1.16); b) la competencia de coordinación general presupone lógicamente que hay algo que debe ser coordinado, esto es, presupone la existencia de competencias de las Comunidades en materia de sanidad, competencias que el Estado, al coordinarlas, debe obviamente respetar, pues nunca ni la fijación de bases ni la coordinación general deben llegar a tal grado de desarrollo que dejen vacías de contenido las correspondientes competencias de las Comunidades; c) la competencia estatal de coordinación general significa no sólo que hay que coordinar las partes o subsistemas (esto es, las competencias comunitarias) del sistema general de sanidad, sino que esa coordinación le corresponde hacerla al Estado; y d) en consecuencia, la coordinación general debe ser entendida como la fijación de medios y de sistemas de relación que hagan posible la información recíproca, la homogeneidad técnica en determinados aspectos y la acción conjunta de las

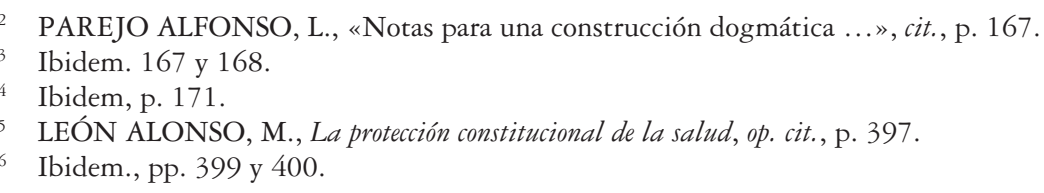


autoridades sanitarias estatales y comunitarias en el ejercicio de sus respectivas competencias de tal modo que se logre la integración de actos parciales en la globalidad del sistema sanitario (FJ 2. ${ }^{\circ}$ ).

Y en la más reciente Sentencia 99/2017 añade, con cita de reiterada jurisprudencia, que la coordinación general debe ser entendida como la fijación de medios y de sistemas de relación que hagan posible la información recíproca, la homogeneidad técnica en determinados aspectos y la acción conjunta de las autoridades estatales y autonómicas en el ejercicio de sus respectivas competencias; de tal modo que se logre la integración de actos parciales en la globalidad del sistema sanitario (por todas, SSTC 32 y 42/1983, 22/2012, 33 y 64/2017).

La Sentencia 63/2017 declara que la utilización de la supraterritorialidad como criterio determinante para la atribución o el traslado de la titularidad de competencias al Estado en ámbitos, en principio, reservados a las competencias autonómicas tiene carácter excepcional, de manera que sólo podrá tener lugar cuando no quepa establecer ningún punto de conexión que permita el ejercicio de las competencias autonómicas o cuando además del carácter supraautonómico del fenómeno objeto de la competencia, no sea posible el fraccionamiento de la actividad pública ejercida sobre él y, aun en este caso, siempre que dicha actuación tampoco pueda ejercerse mediante mecanismos de cooperación o de coordinación y, por ello, requiera un grado de homogeneidad que sólo pueda garantizar su atribución a un único titular, forzosamente el Estado, y cuando sea necesario recurrir a un ente supra-ordenado con capacidad de integrar intereses contrapuestos de sus componentes parciales, sin olvidar el peligro inminente de daños irreparables, que nos sitúa en el terreno del estado de necesidad.

Por su lado, la Sentencia de la Sala de lo Contencioso-administrativo del Tribunal Supremo de 11 de julio de 2000 señala que la coordinación constituye un límite al ejercicio de las competencias de los entes coordinados, mientras que la colaboración o cooperación no puede ser utilizada para limitar el ejercicio de las competencias de los entes territoriales y cuando existe la atribución de una competencia de coordinación, es posible establecer medidas necesarias y suficientes para lograr los objetivos que la coordinación persigue. Y añade, además, que no puede tampoco olvidarse que las funciones atribuidas a los órganos de colaboración son ordinariamente deliberantes o consultivas, lo que evidencia que su interferencia en el ejercicio de las competencias por sus titulares efectivos queda en cualquiera de los casos total y absolutamente preservada, mientras que, en sentido estricto, la coordinación, como ha dicho reiteradamente el Tribunal Constitucional, implica un límite efectivo al ejercicio de las competencias y que, por ello mismo, debe venir, en efecto, amparada en la pertinente atribución competencial normativa.

En lo que se refiere a la función de coordinación en situaciones de excepcionalidad como la que constituye el actual estado de alarma, no existe doctrina del Tribunal Constitucional que lo haya abordado de manera directa o que, incluso, se haya pronunciado sobre la distribución de competencias y estado de alarma. Sin embargo, en 
la Sentencia 133/1990, que no venía referida a un supuesto de estado de alarma, sino a un recurso de inconstitucionalidad promovido por el Gobierno Vasco contra la Ley 2/1985, de 21 de enero, de protección civil, hace referencia a en qué medidas las situaciones de catástrofe pueden suponer un traslado de las competencias autonómicas en favor del Gobierno de la Nación. Así, el Alto Tribunal considera que la competencia autonómica se encuentra con determinados limites, que derivan de la existencia de un posible interés nacional o suprautonómico que pueda verse afectado por la situación de catástrofe o emergencia: Bien por la necesidad de prever la coordinación de Administraciones diversas, bien por el alcance del evento (afectando a varias Comunidades Autónomas) o bien por sus dimensiones, que pueden requerir una dirección nacional de todas las Administraciones públicas afectadas, y una aportación de recursos de nivel suprautonómico. Y, como consecuencia, e íntimamente en relación con tal posibilidad, no pueden negarse al Estado las potestades necesarias para obtener y salvaguardar una coordinación de distintos servicios y recursos pertenecientes a múltiples sujetos, así como (si fuera necesario) para garantizar una dirección y organización unitarias: Esto es, tanto competencias de tipo normativo (disponiendo e instrumentando técnicas de coordinación) como de tipo ejecutivo, asumiendo las instancias estatales tareas de dirección. Las competencias asumidas por las Comunidades Autónomas encuentran pues, su límite, en la importancia de la emergencia, o por la necesidad de una coordinación que haga posible prevenir y, en su caso, reducir los efectos de posibles catástrofes o emergencias de alcance supraautonómico.

La propia coordinación como expresión de la indispensable relación entre el Estado y las Comunidades Autónomas en el ámbito de la salud aparece expresamente proclamada como materia que es competencia de aquél en el art. 149.1.16. ${ }^{a}$ de la Constitución: coordinación general de la sanidad, siendo una expresión concreta del principio de coordinación proclamado en el art. 103 de la Constitución. Y tal deber de coordinación por parte del Estado central se desarrolla inicialmente en la Ley General de Sanidad y a tal fin responde la propia creación de un Sistema Nacional de Sanidad que, según la Exposición de Motivos de la propia Ley, «se concibe así como el conjunto de los servicios de salud de las Comunidades Autónomas convenientemente coordinados», aunque también es cierto que el uso que el propio texto constitucional del término puede entenderse que hace referencia a cualquiera de las dos técnicas de colaboración, es decir, a la cooperación y a la coordinación ${ }^{47}$.

Y añade, a los mismos efectos, el art. 4.1 de la Ley que «Tanto el Estado como las Comunidades Autónomas y las demás Administraciones públicas competentes, organizarán y desarrollarán todas las acciones sanitarias a que se refiere este título dentro de una concepción integral del sistema sanitario». El Capítulo IV de la Ley se dedica a la coordinación general sanitaria.

47 BOUAZZA ARIÑO, O., «Principio de coordinación», en SANTAMARÍA PASTOR, J.A. (Dir.), Los principios jurídicos del Derecho Administrativo, La Ley, Madrid, 2010, pp. 925 y 926. 
El modelo desplegado por la citada Ley General de Sanidad y se complementa después en la Ley 16/2003, cuya Exposición de Motivos dispone a este respecto que «La experiencia en coordinación sanitaria desde la aprobación de la Ley General de Sanidad hace necesaria la búsqueda de un nuevo modelo, que aproveche esa experiencia y ofrezca nuevos instrumentos que permitan a los ciudadanos recibir un servicio sanitario público de calidad y en condiciones de igualdad efectiva en el acceso, independientemente del lugar de su residencia» ${ }^{48}$. Y en ese nuevo modelo, «El órgano básico de cohesión es el Consejo Interterritorial del Sistema Nacional de Salud, al que se dota de mayor agilidad en la toma de decisiones y de mecanismos para la búsqueda de consensos, así como para la vinculación entre las partes en la asunción de estas decisiones».

El art. 1 dispone como objeto de la propia Ley 16/2003, «establecer el marco legal para las acciones de coordinación y cooperación de las Administraciones públicas sanitarias, en el ejercicio de sus respectivas competencias, de modo que se garantice la equidad, la calidad y la participación social en el Sistema Nacional de Salud, así como la colaboración activa de éste en la reducción de las desigualdades en salud», siendo un principio informador, según el art. 2: «c) La coordinación y la cooperación de las Administraciones públicas sanitarias para la superación de las desigualdades en salud, en los términos previstos en esta Ley y en la Ley General de Salud Pública». Tal coordinación y cooperación se extiende, según el tenor del art. 5, a la «h) La salud pública».

Y añade el art. 11.2 in fine que «La prestación de salud pública incluirá, asimismo, todas aquellas actuaciones singulares o medidas especiales que, en materia de salud pública, resulte preciso adoptar por las autoridades sanitarias de las distintas Administraciones públicas, dentro del ámbito de sus competencias, cuando circunstancias sanitarias de carácter extraordinario o situaciones de especial urgencia o necesidad así lo exijan y la evidencia científica disponible las justifique». Tales «prestaciones de salud pública se ejercerán con un carácter de integralidad, a partir de las estructuras de salud pública de las Administraciones y de la infraestructura de atención primaria del Sistema Nacional de Salud» (art. 11.3).

Estas dos técnicas de colaboración de diferentes Administraciones territoriales, Estado central y Comunidades Autónomas, puede llevarse a cabo a través de fórmulas institucionalizadas o fórmulas ad hoc. La fórmula institucionalizada sería la de la Conferencia Sectorial. Y a este respecto, el art. 147 de la Ley 40/2015 define las Conferencias Sectoriales como órgano de cooperación, de composición multilateral y

48 Pemán Gavín recuerda que la Ley 16/2003 ofrece muchos elementos novedosos en materia de coordinación sanitaria, ya que, no en vano, la iniciativa legislativa auspiciada inicialmente, tanto desde el Ministerio de Sanidad como desde el que entonces era el principal partido de la oposición (el Partido Socialista), se concebía como una «Ley de coordinación sanitaria». Aunque luego sería rebautizada como «Ley de cohesión y calidad», ello no obsta por supuesto para que la misma dedique una atención prioritaria a las cuestiones vinculadas con la coordinación. Vid. PEMÁN GAVÍN, J. M., «La nueva configuración del Sistema Nacional de Salud ...», cit., p. 181. 
ámbito sectorial determinado, que reúne, como Presidente, al miembro del Gobierno que, en representación de la Administración General del Estado, resulte competente por razón de la materia, y a los correspondientes miembros de los Consejos de Gobierno, en representación de las Comunidades Autónomas y de las Ciudades de Ceuta y Melilla $^{49}$. Y siendo sus funciones según el art. 148 de la misma Ley tanto consultivas, como decisorias o de coordinación orientadas a alcanzar acuerdos sobre materias comunes. En concreto, entre otras, le corresponde el establecer planes específicos de cooperación entre Comunidades Autónomas en la materia sectorial correspondiente, procurando la supresión de duplicidades, y la consecución de una mejor eficiencia de los servicios públicos.

Interesa también destacar el cambio operado por el art. 70 de la Ley 16/2003, que altera sustancialmente la composición del Consejo en comparación con la regulación contenida en la Ley General de Sanidad y, en especial, en el artículo 47.1. El art. 70, a diferencia de éste, dispone que estará constituido por el Ministro de Sanidad y Consumo, que ostentará su presidencia, y por los Consejeros competentes en materia de sanidad de las comunidades autónomas. La vicepresidencia de este órgano la desempeñará uno de los Consejeros competentes en materia de sanidad de las comunidades autónomas, elegido por todos los Consejeros que lo integran. Y este tenor literal se corresponde con lo dispuesto en el art. 147 de la Ley 40/2015, cuando señala que las Conferencias Sectoriales están integradas por un miembro del Gobierno que, en representación de la Administración General del Estado, resulte competente por razón de la materia, y como Presidente de la Conferencia, y los correspondientes miembros de los Consejos de Gobierno, en representación de las Comunidades Autónomas y de las Ciudades de Ceuta y Melilla.

\subsubsection{El Consejo Interterritorial como expresión institucionalizada del sistema de} relaciones interadministrativas

Visto lo que acabamos de exponer acerca de las dos técnicas de colaboración y del tenor literal de los preceptos que regulan la figura del Consejo Interterritorial en cuanto a su naturaleza y funciones creemos que puede perfectamente afirmarse que el Consejo constituiría, como ya hemos adelantado antes, una expresión institucionalizada del

$49 \mathrm{Al}$ amparo de una de las propuestas contenidas en el Informe de la Comisión de Expertos sobre Autonomías constituida en el Centro de Estudios Constitucionales de 1981, se incluyó en la Ley 12/1983, de 14 de octubre, del Proceso Autonómico, en su art. 4, la figura de la Conferencia Sectorial. Su apartado 1 dispone que «A fin de asegurar en todo momento la necesaria coherencia de la actuación de los poderes públicos y la imprescindible coordinación, se reunirán de forma regular y periódica, al menos dos veces al año, Conferencias sectoriales de los Consejeros de las distintas Comunidades Autónomas y del Ministro o Ministros del ramo, bajo la presidencia de uno de éstos con el fin de intercambiar puntos de vista y examinar en común los problemas de cada sector y las acciones proyectadas para afrontarlos y resolverlos».

(C) UNED. Revista de Derecho Politico 
sistema de relaciones interadministrativas en el ámbito de las competencias en materia de salud, respondiendo a la fórmula de Conferencia Sectorial.

Ciertamente ello no constituye un debate nuevo en la doctrina. Varios autores se pronunciaron hace dos décadas en contra de la consideración del Consejo Interterritorial como Conferencia Sectorial, calificando a aquél de mero órgano colegiado estatal con representantes autonómicos ${ }^{50}$. Sin embargo, dicha posición doctrinal se formuló antes de la aprobación de la Ley 16/2003. Y dentro de dicha reforma destacaría la alteración de la composición del Consejo que abandona el modelo inicial paritario en favor de uno en el que la Administración General del Estado y las Comunidades Autónomas disponen de un mismo nivel de representación, lo cual informa a favor de su consideración como Conferencia Sectorial ${ }^{51}$.

También, las funciones del Consejo se ven fortalecidas a través de dicha reforma legal de 2003, sobre todo, en lo que se refiere a las potestades de coordinación. De este modo, las también objeciones a considerar que el Consejo ejerce una coordinación más formal que material, en la medida que tal coordinación no tendría carácter jerárquico o de supremacía, sino una potestad entre iguales, que es fruto de la voluntad común de todos los entes, por lo que se basa en la autocoordinación, sin que quepa admitir un cierto poder directivo de la unidad superior, tampoco parece que puedan sostenerse $\mathrm{ya}^{52}$.

Así pues, el Consejo es un órgano de cooperación, sanitaria, y ámbito sectorial determinado, sanidad, y de composición multilateral, integrado, como Presidente, por el miembro del Gobierno que, en representación de la Administración General del Estado, resulte competente por razón de la materia, véase, el Ministro de Sanidad, y los correspondientes miembros de los Consejos de Gobierno, en representación de las Comunidades Autónomas y de las Ciudades de Ceuta y Melilla, es decir, los Consejeros autonómicos de Sanidad. Y sus funciones ordinarias tienen, entendemos, pleno encaje en las que la Ley 40/2015 atribuye a una Conferencia Sectorial, aunque contextualizadas en el ámbito de la protección de la salud y con algunas funciones de

50 Vid., en especial, SALA ARQUER, J. M. y VILLAR ROJAS, F., «Análisis de la cooperación en un sector determinado: la sanidad pública», Derecho y Salud, vol. 10, núm. 1, enero-junio 2002, pp. 84 a 86. Los propios autores reconocen en su trabajo, anterior a la aprobación de la Ley 16/2003, que el Consejo Interterritorial ha desempeñado a lo largo de estos años una función análoga a las Conferencias Sectoriales, ejerciendo competencias de coordinación y planificación. También Tornos Mas considera que el Consejo Interterritorial no es una Conferencia Sectorial, un lugar de encuentro entre Gobierno central y Comunidades Autónomas para tratar de articular fórmulas de colaboración, sino que es un órgano de la Administración central en el que se concreta la función de coordinación que pertenece al Estado", por lo que es esencial tener en cuenta que "puede ejercer funciones propias de coordinación que no podrían atribuirse a una Conferencia Sectorial. Vid. TORNOS MAS, J., «Sistema de Seguridad Social versus Sistema Nacional de Salud», Derecho y Salud, vol. 10, núm. 1, año 2002, p. 10.

51 ESCRIBANO COLLADO, P., «La cohesión del Sistema Nacional de Salud ...», cit., p. 24.

52 Vid., en especial, BELTRÁN AGUIRRE, J. L., «La igualdad básica, la coordinación y la cooperación interterritorial: ...», cit., p. 135. 
naturaleza extraordinaria, para tiempos en los que la coordinación cobra especial relevancia, como la que estamos viviendo.

La propia página web del Consejo Interterritorial, al definir su naturaleza, dispone que es, conforme a las previsiones de la Ley 40/2015, la de una Conferencia Sectorial, ya que reúne todos los requisitos establecidos por esta norma para tal consideración, aunque en este caso, como el Consejo de Política Fiscal y Financiera o el Consejo General de la Ciencia y la Tecnología, exista una Ley estatal, la Ley 16/2003, de 28 de mayo, de cohesión y calidad del SNS, que lo regula, de manera compatible y coherente con la citada Ley 40/2015, de 1 de octubre ${ }^{53}$. También, en la relación de Conferencias Sectoriales que publica la página web del Ministerio de Política Territorial y Función Pública actualizada a marzo de 2021, se incluye el Consejo Interterritorial del Sistema Nacional de Salud, con fecha de constitución el 7 de abril de 1987 y regulación en la Ley 16/2003 ${ }^{54}$.

Y ello también parece venir avalado, más allá de lo que disponen aquéllas, por la opinión de la Sala de lo Contencioso-administrativo del Tribunal Supremo que en su Auto de 30 de septiembre de 2020 (procedimiento 257/2020) afirma, en mención al Consejo Interterritorial, que, dado que en la Conferencia Sectorial participa un miembro del Gobierno, esto es un Ministro, así como representantes de todas las CCAA, lo propio es atribuir la competencia a la Audiencia Nacional.

En todo caso, al margen de las iniciales dudas doctrinales, previas a la reforma del Consejo Interterritorial por la Ley 16/2003, y a las resistencias políticas por muchos conocidas que han tratado de impedir, sobre todo, cuando el partido de turno está en la oposición y no ocupa la cartera del Ministerio de Sanidad, la propia comparación entre las normas que regulan la naturaleza, funciones y objetivos de las Conferencias Sectoriales y la del Consejo Interterritorial ofrece pocas dudas al respecto.

Recurriendo a la metáfora de CRUZ VILLALÓN sobre el jurista persa, si por un momento, dicho jurista que habita en un rincón recóndito de Persia y que carece de cualquier tipo de información acerca de España, por una misteriosa razón desea conocer cuál es la naturaleza del Consejo Interterritorial y, en concreto, si se corresponde con la de una Conferencia Sectorial en los términos que se expresa la literalidad de la Ley 16/2003 y la Ley 40/2015, ¿qué es lo que nuestro investigador sacaría en limpio, una vez ha conseguido poner un relativo orden en sus ideas? ${ }^{55}$.

$\mathrm{Y}$ cierto es que en nuestro sistema de organización territorial existen otros órganos colegiados de coordinación cuya naturaleza es discutible que encaje en la categoría

53 Puede accederse a la página web del Consejo Interterritorial a través del siguiente enlace: https://www.mscbs.gob.es/organizacion/consejoInterterri/introduccion.htm. Último acceso el 1 de mayo de 2021.

54 Puede accederse a tales datos a través de la página web del Ministerio de Política Territorial y Función Pública, en https://www.mptfp.gob.es/portal/politica-territorial/autonomica/coop_autonomica/ Conf_Sectoriales.html. Último acceso el 1 de mayo de 2021.

${ }_{55}$ CRUZ VILLALÓN, P., La curiosidad del jurista persa, y otros estudios sobre la Constitución, CEPC, 2. ${ }^{a}$ ed., Madrid, 2006, p. 377.

(C) UNED. Revista de Derecho Politico

N. ${ }^{112}$, septiembre-diciembre 2021, págs. 43-77 
legal de Conferencia Sectorial, siendo el ejemplo común el Consejo de Política Fiscal y Financiera que aparece regulado en el art. 3 de la Ley Orgánica 8/80, de 22 de septiembre, de Financiación de las Comunidades Autónomas. De hecho, alguna voz que niega la condición de Conferencia Sectorial al Consejo Interterritorial arguye que éste no sería el único ejemplo de tertium genus en el mundo de las Conferencias, trayendo a colación la controvertida naturaleza del Consejo de Política Fiscal y Financiera. Sin embargo, la comparación no sea, quizás, acertada en atención no solo a las facultades de coordinación que corresponden a uno y a otro, sino a las propias diferencias de calado entre la distribución de las competencias sanitarias y fiscal y financiera, atendidos los términos de los arts. 148 y 149 de la Constitución, y pese a que las Comunidades Autónomas gocen de autonomía financiera para el desarrollo y ejecución de las competencias que, de acuerdo con la Constitución, les atribuyan las Leyes y sus respectivos Estatutos.

El propio PEMÁN GAVÍN va más allá de la consideración del Consejo Interterritorial como Conferencia Sectorial y lo califica, tras la reforma operada por la Ley 16/2003, como verdadero órgano de gobierno del Sistema Nacional de Salud, utilizando la expresión «gobierno» como concepto que aglutina a todo un extenso abanico de atribuciones políticas y administrativas incluyendo la adopción de numerosas y relevantes decisiones que afectan al conjunto del Sistema, una amplia participación en el ejercicio de la función normativa y, en general, el ejercicio de funciones de carácter directivo sobre el conjunto del Sistema Nacional de Salud ${ }^{56}$. Y añade que se ha consagrado una fórmula de gobierno colegiado de nuestro sistema sanitario, a través de un órgano peculiar que constituye un unicum — no asimilable por completo a ningún otro de los existentes en nuestra compleja organización pública-, que se ha concebido como pieza central para hacer compatibles descentralización y unidad en el ámbito de la Sanidad ${ }^{57}$.

Así pues, el Consejo Interterritorial constituye, como mínimo, una expresión de Conferencia Sectorial, aunque, incluso, con competencias y facultades en el ámbito de la materia de la salud superiores a los de aquélla.

\subsection{La función de actuaciones coordinadas en materia de salud pública}

Siendo ya, creemos, pacífica la naturaleza del Consejo Interterritorial como Conferencia Sectorial en el ámbito de la salud, cobra interés ahora valorar cuál es el propio régimen de las decisiones para, a partir de ahí, poder determinar la propia naturaleza de la Estrategia como decisión impulsada y confirmada por aquél.

El régimen de los acuerdos de las Conferencias Sectoriales se contiene en la Ley 40/2015, con algunas previsiones específicas para el Consejo Interterritorial en la Ley General de Sanidad y en la Ley 16/2003.

56 PEMÁN GAVÍN, J. M., «La nueva configuración del Sistema Nacional de Salud ...», cit., p. 195.

57 Ibidem., p. 195. 
El art. 151 de la Ley 40/2015 dispone que las decisiones que adopte la Conferencia Sectorial podrán revestir dos formas distintas: la de compromiso y la de acuerdo. La modalidad de compromiso se refiere a aquellas decisiones que tienen como finalidad expresar su opinión sobre un asunto que se somete a la consulta de la Conferencia Sectorial. Los miembros de la Conferencia Sectorial se comprometen a orientar su actuación en esa materia de conformidad con lo previsto en la Recomendación salvo quienes hayan votado en contra mientras no decidan suscribirla con posterioridad.

Esta modalidad, no parece responder a la verdadera naturaleza y fines de la Estrategia ya que ésta busca lograr una decisión vinculante para todas las Comunidades Autónomas de manera que, entre otros, se respete el principio de igualdad en el acceso a las vacunas.

La segunda modalidad de decisión que se recoge en el art. 151 de la Ley 40/2015 es el acuerdo. Este supone un compromiso de actuación en el ejercicio de las respectivas competencias. Son de obligado cumplimiento y directamente exigibles de acuerdo con lo previsto en la Ley 29/1998, de 13 de julio, reguladora de la Jurisdicción Contencioso-administrativa, salvo para quienes hayan votado en contra mientras no decidan suscribirlos con posterioridad.

Esta última regla que permite eximirse de la obligatoriedad del acuerdo a quienes hayan votado en contra, encuentra, sin embargo, una excepción en el siguiente párrafo del mismo precepto que dispone que cuando la Administración General del Estado ejerza funciones de coordinación, de acuerdo con el orden constitucional de distribución de competencias del ámbito material respectivo, el acuerdo que se adopte en la Conferencia Sectorial, y en el que se incluirán los votos particulares que se hayan formulado, será de obligado cumplimiento para todas las Administraciones Públicas integrantes de la Conferencia, con independencia del sentido de su voto.

La eficacia de dicho acuerdo de coordinación no exige, por cierto, su publicación en el BOE, ya que ello solo se prevé en el siguiente párrafo cuando la Conferencia Sectorial adopte un plan conjunto para comprometer actuaciones conjuntas para la consecución de los objetivos comunes. BELTRÁN AGUIRRE señalaba hace unos años que la coordinación general de la sanidad no se sitúa en el nivel normativo, sino en el ámbito de la programación de las actuaciones y de las prestaciones sanitarias, porque su fin no es alterar las competencias autonómicas ${ }^{58}$.

Y a estos efectos, resulta de interés citar la Sentencia de la Sala de Vacaciones del Tribunal Superior de Justicia de Madrid de 28 de agosto de 2020 (Sentencia núm. 594/2020), que dispone que, habiendo otorgado el juez a quo una relevancia tal a la falta de publicación en el Boletín Oficial del estado de la Orden del Ministerio de Sanidad por la que se aprueba la Declaración de Actuaciones Coordinadas en Salud Publica, es importante matizar que la falta de publicación de una norma

58 BELTRÁN AGUIRRE, J. L., "Coordinación general sanitaria», en VVAA, Ciudadanía sanitaria. Oportunidades de actualización e integración normativa del Sistema Nacional de Salud en el siglo XXI, Foro SESPAS- Asociación de Juristas de la Salud, vol. 15, núm. 2, año 2007, p. 8.

(C) UNED. Revista de Derecho Politico 
jurídica no afecta a su validez —único extremo que asociaría la sanción jurídica de nulidad de pleno derecho - sino a su eficacia, concepto jurídico diferente. Y derivando la Orden impugnada de una declaración de medidas que relaciona, como actuaciones coordinadas en materia de salud pública, para responder a la situación de especial riesgo derivada del incremento de casos positivos por COVID-19, en armonía con las previsiones del art. 65 de la Ley 16/2003, en la modificación operada por el Real Decreto Ley 21/2020, es obligado colegir que las actuaciones coordinadas en salud pública y las medidas en que se traducen tienen por directo destinatario a las autoridades sanitarias autonómicas, como interlocutores de la administración del Estado, a quienes vinculan y no a los ciudadanos por lo que, como tal instrumento intergubernamental de armonización y homogeneización, su publicación en el Boletín Oficial del Estado resulta irrelevante pues, nada aporta sobre su validez y eficacia, tampoco sobre la concurrencia de una causa de nulidad de pleno derecho no convalidable, ni de un conflicto entre normas que ponga en juego la cláusula de supletoriedad del artículo 149.3 C.E.

La misma doctrina recoge la Sala de lo Contencioso-administrativo de la Audiencia Nacional de 21 de septiembre de 2020, cuando afirma que el acuerdo del Consejo Interritorial de los sistemas de salud que se recoge en la Orden comunicada recurrida solo tiene eficacia vinculante para las CCAA a las que se notificó.

A la vista de todo ello, ¿cabría afirmar que, en el caso concreto de la Estrategia, está actuando la Administración General del Estado, el Ministerio de Sanidad, en el ejercicio de sus funciones de coordinación, de acuerdo con el orden constitucional de distribución de competencias del ámbito material respectivo?

Entendemos que la pregunta solo puede recibir una respuesta positiva, y no solo

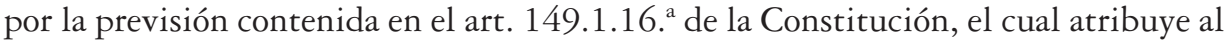
Estado, entre otras competencias exclusivas en materia sanitaria la coordinación general de la sanidad, lo que es una expresión concreta del principio de coordinación proclamado en el art. 103 de la Constitución, sino también por el tenor del art. 65 de la Ley 16/2003, que aparece citado por la Sentencia de la Sala de Vacaciones del Tribunal Superior de Justicia de Madrid de 28 de agosto de 2020 que acabamos de mencionar con ocasión del debate acerca de la necesidad de publicación o no de los acuerdos de coordinación de las Conferencias Sectoriales.

Dicho art. 65 fija un marco jurídico para las que denomina actuaciones coordinadas en materia de salud pública. Y así, establece, en su apartado 1, que la declaración de actuaciones coordinadas en salud pública corresponderá al Ministerio de Sanidad y Consumo, previo acuerdo del Consejo Interterritorial del Sistema Nacional de Salud, con audiencia de las comunidades directamente afectadas, salvo en situaciones de urgente necesidad, en cuyo caso se tomarán las medidas que sean estrictamente necesarias y se le informará de manera inmediata de las medidas adoptadas.

Tal precepto encuentra encaje en un precepto aprobado previamente en la Ley General de Sanidad, el art. 26.1 que dispone que «En caso de que exista o se 
sospeche razonablemente la existencia de un riesgo inminente y extraordinario para la salud, las autoridades sanitarias adoptarán las medidas preventivas que estimen pertinentes». Previsión que se completa en cuanto a las medidas de naturaleza más ablatoria con la escueta como pero muy gráfica regulación contenida en la Ley Orgánica 3/1986, de 14 de abril, de Medidas Especiales en Materia de Salud Pública ${ }^{59}$. De hecho, el art. 65 de la Ley 16/2003 viene a desarrollar un mecanismo administrativo de coordinación y cooperación en la adopción de medidas, dado que el art. 1 de la Ley Orgánica 3/1986 permite una actuación unilateral de cada Administración en el marco de sus competencias pero no establece las bases de una actuación coordinada: «Al objeto de proteger la salud pública y prevenir su pérdida o deterioro, las autoridades sanitarias de las distintas Administraciones Públicas podrán, dentro del ámbito de sus competencias, adoptar las medidas previstas en la presente Ley cuando así lo exijan razones sanitarias de urgencia o necesidad».

Y en el apartado 2 del citado art. 65 de la Ley 16/2003 se dispone que la declaración de actuaciones coordinadas obliga a todas las partes incluidas en ella y podrá formalizarse a través de la activación o diseño de planes y estrategias de actuación para afrontar emergencias sanitarias, fórmula ésta, la de la estrategia que fue incorporada a la Ley por reforma operada por la disposición final 2.1 del Real Decreto-Ley 21/2020, de 9 de junio, de medidas urgentes de prevención, contención y coordinación para hacer frente a la crisis sanitaria ocasionada por el Covid-19.

Las previsiones contenidas en la Ley 16/2003 se completan con el ya citado Real Decreto-Ley 21/2020 que dispone en su art. 5 que con arreglo a lo previsto por el art. 65 de la Ley 16/2003 se procederá a la adopción de planes y estrategias de actuación para afrontar emergencias sanitarias, mediante actuaciones coordinadas en salud pública, atendiendo a los distintos niveles de riesgo de exposición y de transmisión comunitaria de la enfermedad COVID-19 para el desarrollo de las distintas actividades contempladas en este real decreto-ley.

Y todo ello, en el marco de la actuación de protección de la salud de los ciudadanos a través de las acciones que tienden a la prevención de la enfermedad del individuo y de la comunidad (ap. 1), y de programas de atención a grupos de población de mayor riesgo (ap. 5) conforme establece el art. 18 de la Ley General de Sanidad.

Así pues, la Estrategia constituiría un acuerdo adoptado por el Ministerio de Sanidad y el Consejo Interterritorial en sus funciones de coordinación en el marco específico de una emergencia sanitaria como es la pandemia y de conformidad con lo dispuesto por el art. 65 de la Ley 16/2003. Y al adoptarse en el marco de las funciones de coordinación que el ordenamiento jurídico atribuye al Ministerio de Sanidad, en situaciones de urgente necesidad, será de obligado cumplimiento para todas las Comunidades Autónomas integrantes del Consejo, con independencia del sentido de

59 Las medidas contenidas en la Ley Orgánica de Medidas Especiales se completan con otras medidas que, por no incidir sobre los derechos fundamentales, no exigen para su regulación la categoría de norma orgánica, se contienen en el art. 54 de la Ley General de Salud Pública. 
su voto, por aplicación del art. 151.2 a), párr. 2. ${ }^{\circ}$, de la Ley 40/2015, el cual regula el régimen de decisiones de las Conferencias Sectoriales.

Y así lo ha entendido el propio Consejo Interterritorial que en el acuerdo adoptado en el plenario de 28 de enero de 2021, decidió, entre otras cuestiones, reafirmar el compromiso de sus miembros con la Estrategia de Vacunación que, junto con los planes de cada territorio que traen causa en la misma, constituye el mejor mecanismo para afrontar el proceso de vacunación en nuestro país de acuerdo a criterios técnicos, éticos y científicos y continuar con el trabajo conjunto y coordinado de actualización de la Estrategia, definiendo los grupos a vacunar según la disponibilidad de dosis, a través del Grupo de Trabajo Técnico, la Ponencia de Vacunas y la Comisión de Salud Pública del propio Consejo. Y señala dicho acuerdo del Consejo in fine que, pese al voto particular de cuatro Comunidades, conforme al segundo párrafo del art. 151.2.a) de la Ley 40/2015, dado que este Acuerdo viene referido a un ámbito material en el que la Administración General del Estado tiene atribuidas funciones de coordinación general de la sanidad, de acuerdo con el orden constitucional de distribución de competencias, este Acuerdo será de obligado cumplimiento para todas las comunidades y ciudades autónomas integrantes del Consejo Interterritorial del Sistema Nacional de Salud, con independencia del sentido de su voto ${ }^{60}$.

Y si bien es cierto que el art. 73 de la Ley 16/2003 dispone, en cuanto al régimen de funcionamiento y acuerdos del Consejo Interterritorial, por un lado, que, para su adecuado funcionamiento, el Consejo Interterritorial aprobará su reglamento interno, $y$, por el otro, que sus acuerdos se plasmarán a través de recomendaciones que se aprobarán, en su caso, por consenso, lo que reitera el Reglamento del propio Consejo Interterritorial aprobado en sesión plenaria de 23 de julio de 2003, art. 14, no creemos que el tenor literal de aquel precepto sea óbice alguno para negarle la condición de Conferencia Sectorial al Consejo ni menos aún para considerar que no operaría las previsiones contenidas en los arts. 151 de la Ley 40/2015 y 65 de la Ley 16/2003, cuando la exigencia de consenso es más bien una aspiración en la toma de decisiones del mismo pero no una regla que impida imponer la obligatoriedad del acuerdo a

60 El dictamen del Consejo de Estado de 22 de marzo de 2021 (exp. 213/20231) señala, en relación a la Ley de la Comunidad Autónoma de Galicia 8/2021, de 25 de febrero, de modificación de la Ley 8/2008, de 10 de julio, de salud de Galicia que el Acuerdo del Consejo Interterritorial sobre la Estrategia de Vacunación, aprobado el 28 de enero de 2021 con la oposición de cuatro comunidades autónomas —entre ellas Galicia-, en el que se prevé que la vacunación «no es obligatoria», se adoptó en ejercicio de las funciones de coordinación atribuidas a la Administración General del Estado por el artículo 65 de la Ley 16/2003, de 28 de mayo, de Cohesión y Calidad del Sistema Nacional de Salud para «responder a situaciones de especial riesgo o alarma para la salud pública». Por ello, su contenido es «de obligado cumplimiento para todas las Administraciones Públicas integrantes de la Conferencia Sectorial, con independencia del sentido de su voto», con arreglo a lo dispuesto en el artículo 151.2.a) de la Ley 40/2015, de 1 de octubre, de Régimen Jurídico del Sector Público. En la medida en que el Acuerdo es expresión de la potestad de coordinación atribuida a la Administración General del Estado por el artículo 149.1.16. ${ }^{a}$ de la Constitución, tiene su fundamento en la Constitución y, por ello, vincula a todos los poderes públicos estatales y autonómicos, tanto a nivel ejecutivo como normativo. 
quienes hayan formulado voto particular negativo cuando de una medida de coordinación en urgencia sanitaria se trate. La propia Exposición de Motivos de la Ley 16/2003 señala que el consenso es una aspiración, no una regla de toma de decisiones: el órgano básico de cohesión es el Consejo Interterritorial al que se dota de mayor agilidad en la toma de decisiones y de mecanismos para la búsqueda de consensos, así como para la vinculación entre las partes en la asunción de estas decisiones. Y el propio adverbio que se usa, «en su caso», equivale a que el consenso se exigirá si es preciso, si es así, o si se diera el caso.

Negar la condición de Conferencia Sectorial al Consejo y restar virtualidad al régimen de adopción y eficacia de sus acuerdos no creemos que tenga fundamento alguno. La exigencia de consenso para la adopción de acuerdos constituye una opción ciertamente excepcional en nuestro Derecho positivo que no deja de plantear algunas dudas aplicativas, pero, sobre todo, que puede resultar problemática para la propia operatividad del Consejo, dado que implica en la práctica el otorgamiento a cada Consejero autonómico de un poder individual de veto ${ }^{61}$.

No podemos negar que la cuestión del régimen de adopción de los acuerdos de las Conferencias Sectoriales es una de las cuestiones más delicadas de su regulación ${ }^{62}$. Sin embargo, la determinación del correspondiente régimen debe establecerse, como venimos sosteniendo, a partir de la distinción entre funciones de cooperación y coordinación, las cuales, aunque quedan enmarcadas dentro del propio concepto amplio de colaboración entre Administraciones, tienen efectos diferentes en cuanto a su eficacia y vinculación para los participantes en la correspondiente Conferencia Sectorial. Y de este modo, si la Conferencia a analizar tuviera asignadas no solo funciones de cooperación, sino también de coordinación, sería harto difícil afirmar que los correspondientes acuerdos en dicho ámbito de la colaboración exigirían unanimidad, cuando la coordinación per se, puede imponerse a los sujetos integrantes de la Conferencia que hayan votado en contra o expresado voto particular. La previsión que contiene el art. 151 de la Ley 40/2015, en su segundo párrafo, resulta muy clarificadora.

VELASCO CABALLERO ${ }^{63}$ considera que, si bien el art. 65 de la Ley 16/2003 se refiere de una manera genérica a las «actuaciones coordinadas», precisando que todas ellas son de obligado cumplimiento, no distingue, sin embargo, entre las actuaciones acordadas por todas consejerías autonómicas (más el Ministerio) y las actuaciones acordadas por mayoría de las Comunidades Autónomas, más el Ministerio de Sanidad. Esta distinción sí está, por el contrario, presente en el art. 151.2 a) de la Ley 40/2015. Por ello, el autor considera que conviene leer los dos textos legales conjuntamente, ya que a partir de ellos pueden diferenciarse tres tipos de medidas sanitarias de emergencia

61 PEMÁN GAVÍN, J. M., «La nueva configuración del Sistema Nacional de Salud ...», cit., pp. 193 y 194.

${ }_{62}$ TAJADURA TEJADA, J., El principio de cooperación en el Estado Autonómico, op. cit., p. 121.

63 Vid. https://franciscovelascocaballeroblog.wordpress.com/2020/10/01/obligado-cumplimiento-de-las-actuaciones-coordinadas-entre-cooperacion-y-coordinacion-sanitarias/. Último acceso el 5 de mayo de 2021.

(C) UNED. Revista de Derecho Politico 
(«actuaciones coordinadas») en el seno del precitado art. 65. Uno de los tipos es propiamente cooperativo, los otros dos son de coordinación (en sentido estricto).

Así, en primer lugar, estarían los acuerdos sanitarios cooperativos en el seno del Consejo Interterritorial del Sistema Nacional de Salud. En el art. 65 se prevé, en primer lugar, que por «acuerdo» de las consejerías autonómicas y el Ministerio de Sanidad, se pueden declarar «actuaciones coordinadas». Allí donde todas las Comunidades Autónomas y el Estado se ponen de acuerdo en torno a unas concretas «actuaciones coordinadas», podemos decir que ha existido, en sentido estricto, cooperación intergubernamental. Aquí el Consejo Interterritorial habría actuado como un órgano de cooperación, esto es, como un tipo especial de conferencia sectorial, que adopta acuerdos vinculantes sólo para las partes que lo suscriben. Esto es, el Consejo Interterritorial actuaría como órgano de cooperación en el que voluntariamente las autoridades autonómicas - junto con el Ministerio de Sanidad- acuerdan ejercer sus respectivas competencias de una misma manera. Ese «acuerdo» al que llegan las autoridades autonómicas y el Ministerio vincula a cada una de las consejerías (y al Ministerio de Sanidad) precisamente porque el «acuerdo» expresa la voluntad convencional de cada Comunidad Autónoma (y del Estado) de vincularse a una determinada forma de ejercer sus competencias. En este sentido, una Comunidad Autónoma que no ha suscrito el «acuerdo» no está vinculada por él.

En segundo lugar, estarían los acuerdos sanitarios de coordinación, en sentido estricto, que están muy vagamente perfilados en el art. 65, pero que están expresamente regulados en el art. 151.2 a) 2. En este caso, los acuerdos de la conferencia sectorial son «de obligado cumplimiento» para todas las Comunidades Autónomas (por tanto, no sólo para las que están conformes). En este caso, en realidad, no es la conferencia sectorial, sino el correspondiente Ministerio, quien adopta la decisión (en nuestro caso, la «declaración de actuaciones coordinadas»). En estos casos ocurre, más bien, que el acuerdo de la conferencia sectorial contiene una propuesta — de la mayoría de las autoridades autonómicas - para que el Ministerio ejerza su competencia exclusiva de coordinación unilateral en un determinado sentido. De esta forma se consigue que la competencia de coordinación del Ministerio - que necesariamente percute sobre las competencias autonómicas - contenga el menor sacrificio posible de esas competencias autonómicas. En estos casos, quien decide es el Ministro, pero por mandato expreso del art. 65 y esa decisión sólo se puede adoptar previa propuesta mayoritaria de las Comunidades Autónomas presentes en la conferencia sectorial (véase, Consejo Interterritorial).

Por último, en tercer lugar, el art. 65 regula expresamente una segunda forma de coordinación sanitaria. Se prevé en la última frase del art. 65.1 que, en situaciones de «urgente necesidad» el Ministro de Sanidad puede «declarar actuaciones coordinadas» de forma inmediata, sin previa propuesta del Consejo Interterritorial. Esta decisión ministerial vincula a todas las autoridades sanitarias autonómicas. Estamos, en este caso, ante la competencia de coordinación que expresamente atribuye el art. 149.1.16 CE al Estado. En este sentido, el art. 65 no atribuiría ninguna competencia de coordinación al Ministerio, pues tal competencia proviene directamente del art. 149.1.16 
CE. El art. 65 simplemente regula el ejercicio de esa competencia. Y lo hace, dentro las opciones posibles, limitando el ejercicio de la potestad ministerial de coordinación inmediata a situaciones de «urgente necesidad».

Y a la vista de la explicación de VELASCO CABALLERO, puede concluirse que la Estrategia de vacunación frente a la Covid-19 constituye una expresión de la segunda de las opciones explicadas más arriba y, por ello, que verla, más bien, como una propuesta del Consejo Interterritorial para que el Ministro de Sanidad ejerza su competencia ordinaria de coordinación, que sólo procede a propuesta del Consejo Interterritorial, que para formular estas propuestas sí puede actuar por mayoría, no siendo necesaria la unanimidad.

En definitiva, la Estrategia que hemos analizado constituiría un acuerdo emitido en el ejercicio de la competencia de coordinación y al amparo de la habilitación que contiene el art. 65 de la Ley 16/2003 en relación con el art. 151.2 a), parr. 2. ${ }^{\circ}$, de la Ley 40/2015. Su eficacia alcanzaría al propio Gobierno central a través del Ministerio de Sanidad y a todas las Comunidades Autónomas, no siendo necesario para generar dicha vinculación que se haya publicado en el BOE. Otra cuestión es si no sería conveniente darle publicidad a la Estrategia más allá de los medios informales como son la propia página web del Ministerio de Sanidad, a través del BOE. Con ello no se estaría tratando de habilitar un mecanismo de control ciudadano y, en su caso, judicial, de los propios argumentos y decisiones de la Estrategia, lo que puede lograrse mediante la impugnación específica de no haber atendido una Administración Sanitaria autonómica la petición de un ciudadano de ser vacunado, sino por razones esencialmente de transparencia. En todo caso, como decimos, ello no resta un ápice de valor jurídico formal y material a la Estrategia según los preceptos analizados en este trabajo, habiéndose cumplido, además, con el deber de publicidad en los términos que establece el art. 4 de la Ley General de Salud Pública, cuando señala que los «ciudadanos, directamente o a través de las organizaciones en que se agrupen o que los representen, tiene derecho a ser informados, con las limitaciones previstas en la normativa vigente, en materia de salud pública por las Administraciones competentes. Este derecho comprende en todo caso, los siguientes: b) Recibir información sobre las actuaciones y prestaciones de salud pública, su contenido y la forma de acceder a las mismas» y el art. 11 de la misma Ley General que dispone que «será pública la composición de los comités o grupos que evalúen acciones o realicen recomendaciones de salud pública, los procedimientos de selección, la declaración de intereses de los intervinientes, así como los dictámenes y documentos relevantes».

Un ejemplo de publicidad formal lo encontramos en la publicación en el BOE de 12 de marzo de 2021, en relación con la Resolución de 11 de marzo de 2021, de la Secretaría de Estado de Sanidad, por la que se publica el Acuerdo del Consejo Interterritorial del Sistema Nacional de Salud sobre la declaración de actuaciones coordinadas frente a la COVID-19 con motivo de la festividad de San José y de la Semana Santa de 2021. Tal Resolución da cuenta de la declaración adoptada para afrontar las citadas vacaciones con un cierre perimetral autonómico al que se ha opuesto la Comunidad de Madrid.

(C) UNED. Revista de Derecho Politico 
Title:

The constitutional competence for health coordination in times of pandemic: Analysis of the nature and effectiveness of the National Vaccination Strategy against covid-19

\title{
Summary:
}

1. INTRODUCTION: FROM IMMUNITY BY INFECTION TO IMMUNITY BY VACCINATION. 2. THE STRATEGY AS AN INSTRUMENT OF SCARCE RESOURCES PRIORITIZATION. 3. LEGAL NATURE OF THE STRATEGY. 3.1. Reasons for determining the legal nature of the Strategy: from the imposition of vaccination to citizens to the imposition of the Strategy to the Autonomous Communities. 3.2. Legal nature of the Interterritorial Council: Sectorial Conference or mere state and regional collegiate body? 3.2.1. Introduction. 3.2.2. The powers of cooperation and coordination. 3.2.3. The Interterritorial Council as an institutionalized expression of an inter-administrative relations. 3.3. The role of coordinated actions in public health matters

\section{Resumen:}

La vacunación frente a la enfermedad de la Covid-19 se muestra como la única alternativa que nos puede permitir superar esta grave pandemia, con la crisis no solo sanitaria, sino social y económica que conlleva. Sin embargo, al ser las vacunas frente a la Covid-19 un recurso sanitario escaso, ello exige establecer una priorización en el acceso a las misma, lo que han llevado a cabo las autoridades sanitarias a través de la Estrategia de vacunación frente a Covid-19 en España. Tal Estrategia puede afirmarse que constituye una expresión de la competencia de coordinación sanitaria que en el marco específico de una emergencia sanitaria como es la pandemia le corresponde al Ministerio de Sanidad y el Consejo Interterritorial en sus funciones de coordinación y de conformidad con lo dispuesto por el art. 65 de la Ley 16/2003.

\begin{abstract}
:
Vaccination against the Covid-19 disease is shown as the only alternative that can allow us to overcome this pandemic, with the crisis not only for health, but also social and economic that it entails. However, since vaccines against Covid-19 are a scarce health resource, this requires prioritizing access to them, which has been carried out by health authorities through the Vaccination Strategy against Covid- 19 in Spain. Such Strategy can be affirmed that it constitutes an expression of the health coordination competence that in the specific framework of a health emergency such as the pandemic corresponds to the Ministry of Health and the Interterritorial Council in their coordination functions and in accordance with the provisions of the Article 65 of Law 16/2003.
\end{abstract}




\section{Palabras-clave:}

Consejo Interterritorial, Ministerio de Sanidad, Estado de las Autonomías, competencia sanitaria, coordinación sanitaria, priorización de recursos escasos, Covid-19, pandemia

\section{Key-words:}

Interterritorial Council, Ministry of Health, State of Autonomies, health competence, health coordination, prioritization of scarce resources, Covid-19, pandemic 